\title{
Transferrin receptor 1 upregulation in primary tumor and downregulation in benign kidney is associated with progression and mortality in renal cell carcinoma patients
}

\author{
Christopher J. Greene ${ }^{1}$, Kristopher Attwood ${ }^{2}$, Nitika J. Sharma ${ }^{1}$, Kenneth W. \\ Gross $^{3}$, Gary J. Smith ${ }^{1}$, Bo Xu' ${ }^{4}$ and Eric C. Kauffman ${ }^{1,5,6}$ \\ ${ }^{1}$ Department of Urology, Roswell Park Cancer Institute, Buffalo, NY 14263, USA \\ ${ }^{2}$ Department of Biostatistics and Bioinformatics, Roswell Park Cancer Institute, Buffalo, NY 14263, USA \\ ${ }^{3}$ Department of Molecular and Cellular Biology, Roswell Park Cancer Institute, Buffalo, NY 14263, USA \\ ${ }^{4}$ Department of Pathology, Roswell Park Cancer Institute, Buffalo, NY 14263, USA \\ ${ }^{5}$ Department of Cancer Genetics, Roswell Park Cancer Institute, Buffalo, NY 14263, USA \\ ${ }^{6}$ Jacobs School of Medicine and Biomedical Sciences, State University of New York at Buffalo, Buffalo, NY 14214, USA \\ Correspondence to: Eric C. Kauffman, email: eric.kauffman@roswellpark.org \\ Keywords: transferrin receptor; iron; renal cell carcinoma; clear cell; immunohistochemistry \\ Received: May 19, $2017 \quad$ Accepted: August 31, $2017 \quad$ Published: November 06, 2017 \\ Copyright: Greene et al. This is an open-access article distributed under the terms of the Creative Commons Attribution License \\ 3.0 (CC BY 3.0), which permits unrestricted use, distribution, and reproduction in any medium, provided the original author and \\ source are credited.
}

\section{ABSTRACT}

The central dysregulated pathway of clear cell (cc) renal cell carcinoma (RCC), the von Hippel Lindau/hypoxia inducible factor-a axis, is a key regulator of intracellular iron levels, however the role of iron uptake in human RCC tumorigenesis and progression remains unknown. We conducted a thorough, large-scale investigation of the expression and prognostic significance of the primary iron uptake protein, transferrin receptor 1 (TfR1/CD71/TFRC), in RCC patients. TfR1 immunohistochemistry was performed in over 1500 cores from 574 renal cell tumor patient tissues (primary tumors, matched benign kidneys, metastases) and non-neoplastic tissues from 36 different body sites. TfR1 levels in RCC tumors, particularly CCRCC, were significantly associated with adverse clinical prognostic features (anemia, lower body mass index, smoking), worse tumor pathology (size, stage, grade, multifocality, sarcomatoid dedifferentiation) and worse survival outcomes, including after adjustments for tumor pathology. Highest TfR1 tissue levels in the non-gravid body were detected in benign renal tubule epithelium. Opposite to TfR1 changes in the primary tumor, TfR1 levels in benign kidney dropped during tumor progression and were inversely associated with worse survival outcomes, independent of tumor pathology. Quantitative measurement of TfR1 subcellular localization in cell lines demonstrated mixed cytoplasmic and membranous expression with increased TfR1 in clusters in CCRCC versus benign renal cell lines. Results of this study support an important role for TfR1 in RCC progression and identify TfR1 as a novel RCC biomarker and therapeutic target.

\section{INTRODUCTION}

More than 60,000 new cases of kidney cancer will be diagnosed this year in the U.S., with over $90 \%$ being renal cell carcinoma (RCC) $[1,2]$. RCC is comprised of different subtypes, each with a distinct histology, genetic mutational profile and clinical behavior, and includes clear cell RCC (ccRCC, 75\%), papillary RCC (pRCC, $15 \%$ ), chromophobe RCC (chRCC, 5\%) and less common subtypes [3-6]. Risk factors include male gender, tobacco, hypertension and obesity, but may vary with RCC subtype $[2,7,8]$. Despite recent clinical advances, RCC diagnoses are increasing annually by $2-3 \%$ without reduction in mortality, and metastatic relapse after nephrectomy for 
localized disease remains a frequent event [9-11]. Current systemic therapies approved for advanced disease achieve only modest survival benefits [12], and no prognostic molecular biomarkers are presently available to guide RCC patient management [13]. Hence there is a critical need for improved prevention and treatment strategies.

Iron is the most abundant transition metal in the human body and a potent catalyst of intracellular oxidative stress, a process heavily implicated in RCC tumorigenesis $[6,14-17]$. Through the Fenton reaction, iron reacts with hydrogen peroxide to produce hydroxyl radicals that act as potent, non-selective oxidizing agents of cellular macromolecules including protein, lipid, carbohydrate and nucleic acids [18, 19]. Oxidative DNA damage can induce gene mutations, chromosomal remodeling and epigenetic instability that may contribute to carcinogenesis [20]. Furthermore, iron drives cell division, a hallmark of tumorigenesis, as the essential cofactor for the ratelimiting step of DNA synthesis, and is also critical for other processes implicated in carcinogenesis, which include chromatin remodeling by the iron-dependent oxidase superfamily; DNA repair by iron-dependent enzymes such as p53R2/RRM2B; cellular/mitochondrial respiration involving iron-sulphur cluster proteins; and cell cycle progression through indirect effects on $\mathrm{p} 53, \mathrm{Rb}$, p21 and p27 [21-24].

The kidney has a unique role in iron physiology, providing the main body source of the hormone, erythropoietin, which mobilizes iron stores via hemoglobin synthesis [25]. Animal studies provide compelling support that iron might play an under-appreciated role in RCC tumorigenesis. Repeated systemic administration of iron to rodents causes iron deposition with oxidative tissue injury in renal tubule epithelium, the presumed site of human RCC tumorigenesis, followed by renal tumorigenesis that mimics human ccRCC in histology, male gender predominance, and metastatic affinity for the lungs and lymph nodes [26-30]. In humans, increased RCC rates are reported among workers in iron/steel industries; and among patients with anemias requiring chronic transfusion, a primary cause of systemic iron overload $[31,32]$. Iron is also a prominent component of tobacco, the most well-established RCC carcinogen [33]. Despite these compelling observations, a role for altered iron metabolism in human RCC has undergone scarce investigation $[34,35]$.

Regulation of intracellular iron metabolism is governed by a distinct set of proteins [36]. The primary protein for intracellular iron uptake is transferrin receptor 1 (TfR1/CD71/ TFRC), which is constitutively endocytosed from the cell membrane upon binding iron with its serum carrier protein, transferrin (Tf). The more recently discovered transferrin receptor 2 (TfR2) has restricted tissue expression (liver, duodenum, erythrocytes) and a minor role in iron uptake $[37,38]$. Intracellular iron transport, storage and export are governed by divalent metal transporter 1 (SLC11A2/ DMT1), ferritin (heavy chain, FTH1, and light chain, FTL), ferroportin (SLC40A1/FPN1) and hepcidin (HAMP). During iron deficiency, iron regulatory proteins (ACO1/IRP1, IREB2/IRP2) increase iron levels by binding to a small subset of mRNA transcripts that harbor an iron responsive element (IRE) to modulate their translation. IRE motifs are restricted to transcripts whose products are critical to iron metabolism, such as TfR1, DMT1, FTH1, FTL and FPN1 [39].

Additional regulation of iron metabolism is provided by the centrally dysregulated pathway of ccRCC, the von Hippel Lindau (VHL)/proline hydroxylase (PHD)/hypoxia inducible factor- $\alpha$ (HIF- $\alpha$ ) axis, which governs the cell response to intracellular oxygen and iron levels [3]. The $V H L$ gene is mutated in $55-75 \%$ of ccRCC patient tumors $[4,40,41]$, and an additional subset of ccRCC tumors harbor VHL promoter hypermethylation [42], resulting in VHL functional loss in approximately $90 \%$ of ccRCC tumors [43, 44]. VHL loss causes HIF- $\alpha$ transcription factor accumulation and transcriptional activation of HIF- $\alpha$ target genes that include the TfR1 gene, TFRC [45-47]. HIF- $2 \alpha$ is believed to be the critical VHL target driving ccRCC carcinogenesis, since HIF- $2 \alpha$ but not HIF- $1 \alpha$ is overexpressed in potentially all VHL-null ccRCC patient tumors [44]; overexpression of HIF-2 $\alpha$ but not HIF-1 $\alpha$ is sufficient to restore ccRCC cell line tumorigenicity suppressed by VHL overexpression [48, 49]; and higher RCC tumor levels of HIF-2 $\alpha$ portend a worse patient prognosis [50]. Intriguingly, an IRE binding site for IRP1 has been identified in the 5' UTR of the HIF-2 $\alpha$ transcript that increases HIF- $2 \alpha$ translation in the presence of iron [51]. However, the role of iron uptake in modulating HIF$2 \alpha$ expression in RCC patient tumors remains unknown.

The current study provides a thorough, large-scale investigation into the level and prognostic significance of TfR1 expression in renal cell tumor patients. Our findings reveal significant associations of TfR1 expression in RCC primary tumors with disease progression and patient mortality, particularly for ccRCC patients. Furthermore, we discover that the highest non-gravid body levels of TfR1 protein are in benign kidney, underscoring a unique role for this protein in renal physiology/disease; and that, opposite to changes in the primary tumor, reductions in benign kidney TfR1 are associated with more aggressive RCC tumors. Together, these data support a complex, tissue-specific role for TfR1 in RCC progression and identify this protein as a novel potential RCC biomarker and therapeutic target.

\section{RESULTS}

\section{TfR1 expression in normal human tissues}

TfR1 protein levels were evaluated by IHC in nonneoplastic human tissue types from two sources: 1) RCC patient tissue microarrays (TMA(s)) which included 14 different normal tissue types as internal staining controls, and 2) a normal tissue TMA surveying 36 different body tissue types (Figure 1). RCC patient TMAs immunostain 
detected little or no TfR1 protein expression $(<5 \%$ percentage of tissue positivity, PTP) in most normal body tissues, with the exception of kidney, adrenal gland and liver, which had moderate to high levels. Highest TfR1 levels were detected in the kidney (Figure 1A) and localized predominantly to the basal membrane and cytoplasm of renal tubule epithelium, without expression in adjacent stroma (Figure 1C). Distal tubule staining intensity was typically high $(3+)$, while proximal tubule staining intensity was typically moderate $(2+)$. Similar results were obtained using the commercial normal tissue TMA, in which only placenta had greater TfR1 expression than kidney among the 36 tissue types tested (Figure 1B, 1D). There was no appreciable difference in TfR1 expression between the renal cortex and renal medulla.

\section{Renal cell tumor patient features}

Among 287 renal cell tumor patients represented on the TMAs, 574 tissues (268 primary tumors, 232 matching normal kidneys, 74 metastases) had adequate TfR1 staining for evaluation (mean/median 2.7/3.0 cores per specimen). Clinicopathologic features of patients and tissues are summarized in Table 1. Most patients had ccRCC, and 11 patients had benign renal tumors (oncocytoma) without evidence of RCC. RCC risk factors of male gender, smoking history, hypertension and obesity (body mass index, BMI, $>30 \mathrm{~kg} / \mathrm{m}^{2}$ ) were common. More than one third of patients were anemic and 13 patients were known to be on iron supplementation. Of the 74 metastasis tissues, most were either ccRCC or an unknown RCC subtype, and only 7 metastasis tissues were from non-ccRCC tumors.

\section{TfR1 expression in benign kidney, primary tumor and metastasis tissues of renal cell tumor patients}

TfR1 protein was detected by IHC at high levels in normal kidney tissue from renal cell tumor patients, similar to levels in non-matching normal kidney tissue controls. Expression was maintained in primary tumors, although at significantly lower levels compared to matching normal renal epithelium (Figure 2A, 2B). The exception was chRCC, which had slightly higher expression of TfR1 (mean $\mathrm{PTP}=83 \%$, mean $\mathrm{H}$-score $=$ 206) than matching benign kidney. Lowest TfR 1 tumor expression was detected in ccRCC tumors (mean PTP= $24 \%$, mean H-score $=50$ ). TfR1 levels in other renal tumor subtypes, including $\mathrm{pRCC}$ or benign oncocytoma, were intermediate between TfR1 levels of ccRCC and chRCC (Figure 2C, 2D, and 2E). In subset analyses limited to matched primary tumor and benign kidney tissues, tumor TfR1 levels remained significantly $(p<0.001)$ lower than normal kidney TfR1 levels; and there was a nonsignificant trend towards a negative correlation between TfR1 levels in tumor and normal kidney from the same patient (Supplementary Table 1).
Mean TfR1 levels in metastases were significantly higher than in primary tumors from metastatic and nonmetastatic patients (Figure 2A, 2B), reaching approximately 2-fold higher levels among ccRCC patients. However, in subset analyses limited to only metastatic patients, TfR1 levels in metastases and primary tumors were nearly identical; and there was a statistically significant correlation of moderate strength between TfR1 levels in primary tumor and metastatic tissue from the same patient (Supplementary Table 2).

TfR1 subcellular localization in tumors and metastases was generally both membranous and cytoplasmic and less frequently nuclear, perinuclear, or isolated membranous without cytoplasmic involvement.

\section{Association of renal cell primary tumor TfR1 expression with preoperative clinical features}

Primary tumor TfR1 protein levels (PTP and H-score) were tested for association with preoperative clinical features of renal cell tumor patients, including known diagnostic and prognostic risk factors (Table 2). Primary tumor TfR1 expression was significantly increased in patients with metastatic stage or certain adverse prognostic risk factors, including a lower BMI and a lower hemoglobin or history of anemia. An iron-deficient type of anemia (and hence the use of iron supplementation) was associated with the highest tumor TfR1 levels among clinical features examined. These findings were confirmed among RCC patients after exclusion of benign oncocytoma patients (data not shown).

Similarly, in the ccRCC subset, significant associations were detected between primary tumor TfR 1 levels and a metastatic stage, lower BMI, lower hemoglobin and history of anemia and iron supplementation; and with greater differences than detected among all RCC patients (Table 2). Although a trend towards association between smoking, an adverse prognostic risk factor, and ccRCC tumor TfR1 H-score did not reach significance $(p=0.053)$, smoking was significantly associated with a higher ccRCC tumor TfR1 maximum staining intensity (MSI) (mean 1.3 for smoking history $v s$. mean 1.0 for no smoking history; $\mathrm{p}=0.022$ ). Highest ccRCC tumor levels of TfR 1 were detected in patients with iron-deficient anemia, who had on average 5-fold higher levels than patients without irondeficient anemia (Table 2).

Similar to ccRCC primary tumors, TfR1 levels in non-ccRCC primary tumors were significantly higher in anemic patients, with highest levels in iron-deficient anemic patients (Table 2). In contrast, neither metastatic stage nor other adverse clinical features were associated with non-ccRCC primary tumor TfR1 levels (Table 2).

\section{Association of renal cell tumor TfR1 levels with tumor pathology}

RCC primary tumor TfR 1 levels were tested for association with adverse pathologic features (Figure 3, Supplementary Figure 1). TfR1 upregulation in primary 
tumors was strongly associated with tumor size, stage and grade $(\mathrm{p}<0.001$ each). Mean TfR1 H-scores in large $(>10 \mathrm{~cm})$ or grade IV tumors were similar to those of metastatic lesions (Figure 3A, 3C). TfR1 expression was also significantly increased in multifocal tumors (Figure 3D). A trend towards association between primary tumor TfR1 H-score and sarcomatoid dedifferentiation was non-significant ( $p=0.073$, Figure $3 \mathrm{E}$ ), however TfR1 staining intensity was significantly associated with sarcomatoid dedifferentiation (mean $\mathrm{MSI}=1.9$ for present vs. 1.2 for absent, $p=0.004$ ) and the tumor percentage of sarcomatoid involvement (mean MSI $=1.2$ for $0 \% ; 1.3$ for $1-50 \%, 2.3$ for $>50 \% ; p=0.013)$. Similar findings were observed whether or not benign oncocytoma patients were included in analyses (data not shown).
Among the ccRCC primary tumor subset, similar significant associations between primary tumor TfR1 levels and all adverse pathologic features (tumor size, stage, grade, multifocality, sarcomatoid presence/percentage) were observed; and were of greater magnitude than observed in the full patient cohort (Figure 3, Supplementary Figure 1). Each stepwise increase in ccRCC tumor stage or grade was associated with an approximate doubling of the tumor TfR1 H-score. Grade IV tumors had $>10$-fold higher TfR1 levels than grade I tumors; pT3/pT4 tumors had $>4$-fold higher levels than pT1 tumors; large tumors $(>10 \mathrm{~cm})$ had $>4$-fold higher levels than small $(\leq 4 \mathrm{~cm})$ tumors.

In contrast to ccRCC tumors, no significant associations between non-ccRCC primary tumor TfR1 levels and adverse pathologic features were detected, with
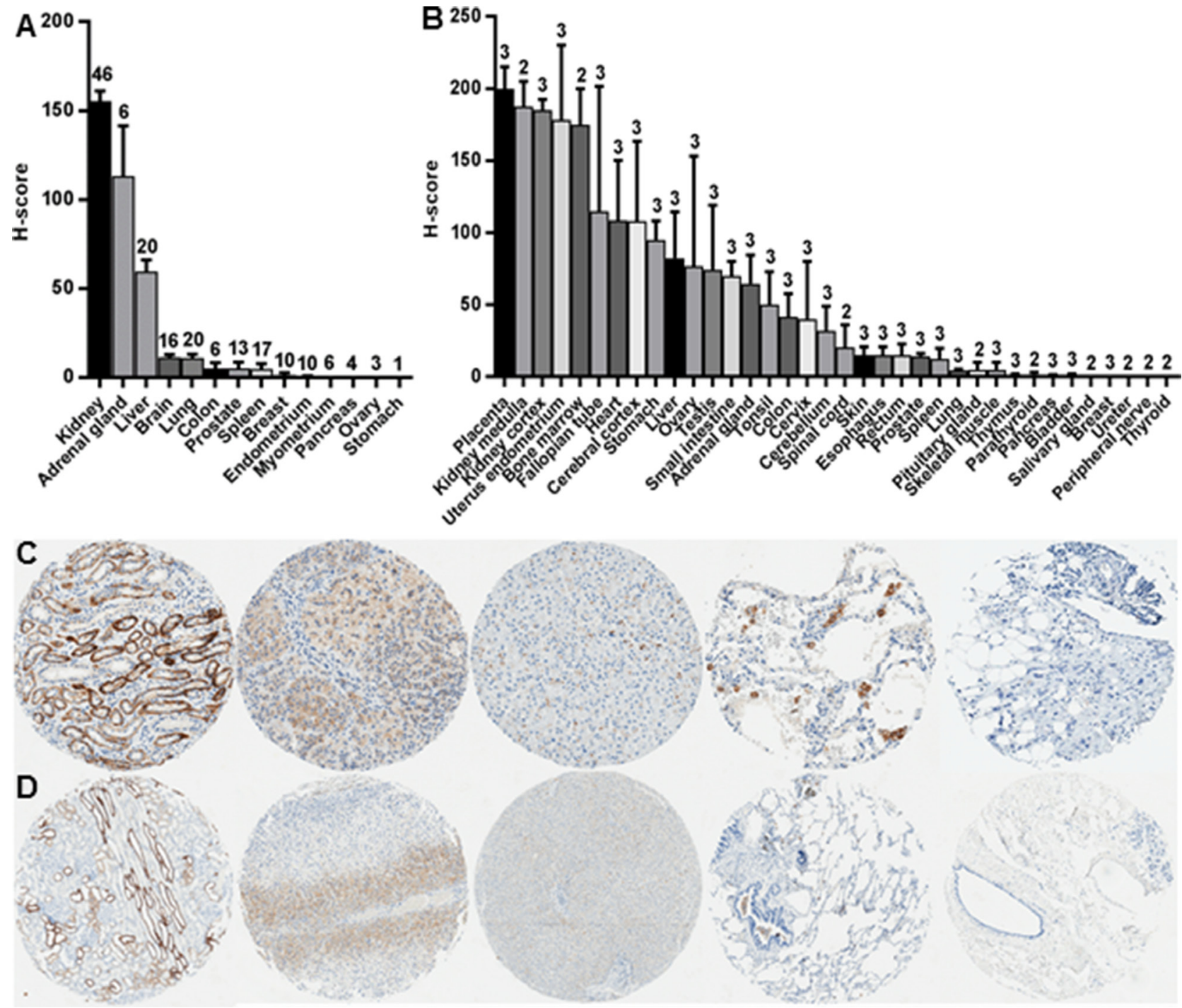

Figure 1: TfR1 levels in normal tissues of various body sites. IHC was performed for TfR1 in normal (non-neoplastic) tissues using two different TMA sources: (A) RCC patient TMAs which included 14 different normal tissue types as internal staining controls; and (B) a normal tissue TMA surveying 36 different body-wide tissue types. Representative tissue cores are shown for (left to right): kidney cortex, adrenal gland, liver, lung and breast from the (C) 14-tissue TMAs and (D) 36-tissue normal TMA. The number of cores evaluated per tissue type is labeled above each error bar. 


\begin{tabular}{|c|c|c|c|c|}
\hline & \multirow[t]{2}{*}{ Patients, n (\%) } & \multicolumn{3}{|c|}{ Tissues, n (\%) } \\
\hline & & Primary Tumor & Benign Kidney & Metastasis \\
\hline Total number & 287 & 268 & 232 & 74 \\
\hline \multicolumn{5}{|l|}{ Age, years } \\
\hline$<=60$ & $155(54.0)$ & $144(53.7)$ & $119(51.3)$ & $52(70.3)$ \\
\hline$>60$ & $132(46.0)$ & $124(46.3)$ & $113(48.7)$ & $22(29.7)$ \\
\hline \multicolumn{5}{|l|}{ Gender } \\
\hline Male & $179(62.4)$ & $166(61.9)$ & $147(63.4)$ & $46(62.2)$ \\
\hline Female & $108(37.6)$ & $102(38.1)$ & $85(36.6)$ & $28(37.8)$ \\
\hline \multicolumn{5}{|l|}{ Race } \\
\hline White & $268(93.4)$ & $252(94.0)$ & $218(94.0)$ & $71(95.9)$ \\
\hline Black & $19(6.6)$ & $16(6.0)$ & $14(6.0)$ & $3(4.1)$ \\
\hline \multicolumn{5}{|c|}{ Body Mass Index, $\mathrm{kg} / \mathrm{m}^{2}$} \\
\hline$<30$ & $109(49.8)$ & $120(51.3)$ & $101(50.8)$ & $16(66.7)$ \\
\hline$>=30$ & $110(50.2)$ & $114(48.7)$ & $98(49.2)$ & $8(33.3)$ \\
\hline \multicolumn{5}{|c|}{ Smoking History } \\
\hline Never & $122(43.7)$ & $118(45.0)$ & $103(45.6)$ & $21(29.2)$ \\
\hline Any & $157(56.3)$ & $144(55.0)$ & $123(54.4)$ & $51(70.8)$ \\
\hline \multicolumn{5}{|c|}{ Smoking Pack-Years } \\
\hline 0 & $122(56.0)$ & $118(52.4)$ & $103(54.2)$ & $21(58.3)$ \\
\hline$<=30$ & $56(25.7)$ & $64(28.4)$ & $49(25.8)$ & $10(27.8)$ \\
\hline$>30$ & $40(18.3)$ & $43(19.1)$ & $38(20.0)$ & $5(13.9)$ \\
\hline \multicolumn{5}{|c|}{$\begin{array}{l}\text { Iron Supplement } \\
\text { Medication }\end{array}$} \\
\hline No & $199(94.8)$ & $213(94.2)$ & $180(94.2)$ & $22(88.0)$ \\
\hline Yes & $11(5.2)$ & $13(5.8)$ & $11(5.8)$ & $3(12.0)$ \\
\hline \multicolumn{5}{|l|}{ Anemia } \\
\hline No & $91(64.1)$ & $92(61.3)$ & $82(62.1)$ & $2(14.3)$ \\
\hline Yes & $51(35.9)$ & $58(38.7)$ & $50(37.9)$ & $12(85.7)$ \\
\hline \multicolumn{5}{|c|}{ Iron-Deficient Anemia } \\
\hline No & $112(90.3)$ & $116(89.9)$ & $103(90.4)$ & $4(50.0)$ \\
\hline Yes & $12(9.7)$ & $13(10.1)$ & $11(9.6)$ & $4(50.0)$ \\
\hline \multicolumn{5}{|c|}{ Hemoglobin level, g/dL } \\
\hline$<13.3$ & $63(44.4)$ & $69(46.0)$ & $60(45.5)$ & $11(78.6)$ \\
\hline$>=13.3$ & $79(55.6)$ & $81(54.0)$ & $72(54.5)$ & $3(21.4)$ \\
\hline \multicolumn{5}{|l|}{ Hypertension } \\
\hline No & $64(32.5)$ & $71(33.3)$ & $61(33.9)$ & $11(45.8)$ \\
\hline Yes & $133(67.5)$ & $142(66.7)$ & $119(66.1)$ & $13(54.2)$ \\
\hline \multicolumn{5}{|c|}{ Histologic Subtype } \\
\hline ccRCC & 195 (67.9) & $203(75.7)$ & $176(75.9)$ & $34(45.9)$ \\
\hline pRCC & $26(9.1)$ & $25(9.3)$ & $22(9.5)$ & $6(8.1)$ \\
\hline
\end{tabular}

(Continued) 


\begin{tabular}{|c|c|c|c|c|}
\hline & \multirow[t]{2}{*}{ Patients, n (\%) } & \multicolumn{3}{|c|}{ Tissues, n (\%) } \\
\hline & & Primary Tumor & Benign Kidney & Metastasis \\
\hline $\operatorname{chRCC}$ & $13(4.5)$ & $12(4.5)$ & $11(4.7)$ & $0(0)$ \\
\hline Other RCC & $3(1.0)$ & $3(1.1)$ & $1(0.4)$ & $1(1.4)$ \\
\hline Unspecified RCC & $39(13.6)$ & $14(5.2)$ & $12(5.2)$ & $33(44.6)$ \\
\hline Oncocytoma & $11(3.8)$ & $11(4.1)$ & $10(4.3)$ & $0(0)$ \\
\hline \multicolumn{5}{|l|}{ Tumor Grade } \\
\hline I & $14(5.4)$ & $13(5.2)$ & $12(5.5)$ & $1(1.6)$ \\
\hline II & $127(49.0)$ & $116(46.2)$ & $104(47.5)$ & $19(30.6)$ \\
\hline III & $72(27.8)$ & $68(27.1)$ & $57(26.0)$ & $20(32.3)$ \\
\hline IV & $46(17.8)$ & $54(21.5)$ & $46(21.0)$ & $22(35.5)$ \\
\hline \multicolumn{5}{|l|}{ Tumor Stage } \\
\hline pT1 & $131(47.5)$ & $131(51.0)$ & $114(51.4)$ & $5(6.8)$ \\
\hline pT2 & 43 (15.6) & $44(17.1)$ & $38(17.1)$ & $8(10.8)$ \\
\hline $\mathrm{pT} 3 / 4$ & $70(25.4)$ & $81(31.5)$ & $69(31.1)$ & $30(40.5)$ \\
\hline $\mathrm{pTx}$ & $32(11.6)$ & $1(0.4)$ & $1(0.5)$ & $31(41.9)$ \\
\hline \multicolumn{5}{|l|}{ Tumor Size, cm } \\
\hline$<=4$ & 97 (35.7) & $94(35.7)$ & $84(37.0)$ & $7(11.5)$ \\
\hline$>4$ and $</=7$ & $84(30.9)$ & $76(28.9)$ & $64(28.2)$ & $20(32.8)$ \\
\hline$>7$ and $</=10$ & $49(18.0)$ & $50(19.0)$ & $45(19.8)$ & $18(29.5)$ \\
\hline$>10$ & $42(15.4)$ & $43(16.3)$ & $34(15.0)$ & $16(26.2)$ \\
\hline \multicolumn{5}{|l|}{ Tumor Focality } \\
\hline Unifocal & $168(88.0)$ & $178(87.3)$ & $155(88.1)$ & $17(81.0)$ \\
\hline Multifocal & $23(12.0)$ & $26(12.7)$ & $21(11.9)$ & $4(19.0)$ \\
\hline \multicolumn{5}{|l|}{$\begin{array}{l}\text { Tumor Presence of } \\
\text { Sarcomatoid }\end{array}$} \\
\hline No & $218(91.6)$ & $230(90.2)$ & $196(89.9)$ & $18(66.7)$ \\
\hline Yes & $20(8.4)$ & $25(9.8)$ & $22(10.1)$ & $9(33.3)$ \\
\hline \multicolumn{5}{|l|}{$\begin{array}{l}\text { Tumor Sarcomatoid } \\
\text { Percentage }\end{array}$} \\
\hline 0 & $220(93.2)$ & $232(91.7)$ & $198(91.7)$ & $20(74.1)$ \\
\hline$<=50 \%$ & $8(3.4)$ & $10(4.0)$ & $8(3.7)$ & $3(11.1)$ \\
\hline$>50 \%$ & $8(3.4)$ & $11(4.3)$ & $10(4.6)$ & $4(14.8)$ \\
\hline
\end{tabular}

the exception that larger non-ccRCC tumors $(>4 \mathrm{~cm})$ had approximately twice as high TfR1 levels as smaller $(\leq 4$ $\mathrm{cm}$ ) non-ccRCC tumors (Figure 3A).

\section{Association of primary tumor TfR1 levels with RCC patient survival}

We next looked at the relationship between primary tumor TfR1 levels and patient survival outcomes (Figure
4, Table 3). In ccRCC patients, primary tumor TfR1 levels (either H-score or PTP) were strongly associated with a shorter time to metastasis $(p<0.001)$, cancer-specific death $(p<0.001)$ or death from any cause $(p<0.001)$ (Figure 4A). In non-ccRCC patients, primary tumor TfR1 levels were associated with significantly worse cancer-specific survival, but not metastasis-free survival or overall survival (Figure 4B). In multivariable analyses adjusting for tumor pathology (and age for overall survival 
analyses), ccRCC primary tumor TfR1 level remained significantly associated with metastasis-free and overall survival outcomes $(\mathrm{p}<0.05$ each); with a strong trend towards a significant independent association with cancerspecific survival $(p=0.055)$. Similar multivariable analyses were not performed among non-ccRCC patients due to an inadequate number of metastasis/death events (Table 3 ).

\section{Association of metastasis TfR1 levels with RCC patient clinicopathologic features and survival}

Similar analyses were performed to test the association between metastasis TfR1 levels and patient clinical features, primary tumor pathology and survival outcomes. There was no significant association between
TfR1 levels in metastases and clinical or pathologic features, with the exception of primary tumor grade (Supplementary Figure 2). Metastasis TfR1 levels were not associated with cancer-specific or overall survival outcomes (Supplementary Table 3).

\section{Association of benign kidney TfR1 levels with renal cell tumor patient clinical features and pathology}

In addition to TfR1 levels in primary tumors and metastases, we tested TfR1 levels in benign kidney for association with renal cell tumor patient clinical features and pathology. Anemia and an extensive smoking history were each associated with significant decreases in benign
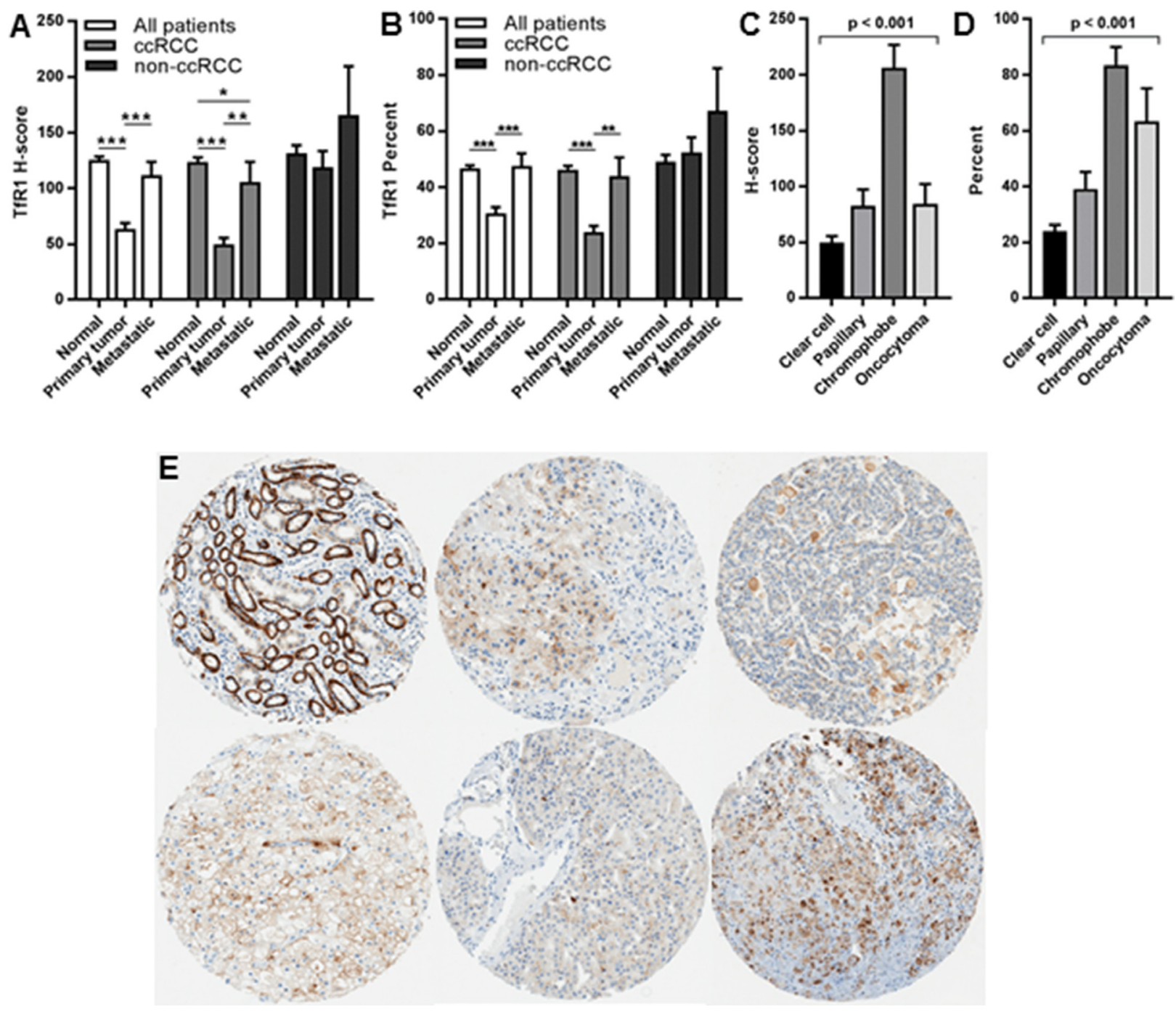

Figure 2: TfR1 levels in normal kidney, primary tumors and metastases of renal cell tumor patients. IHC was performed for TfR1 using renal cell tumor patient TMAs. TfR1 levels were compared among normal (non-neoplastic) kidney, primary tumors and metastatic lesions, based on (A) mean H-score and (B) mean PTP. TfR1 levels were compared among different renal cell primary tumor subtypes based on (C) mean H-score and (D) mean PTP. (E) Representative images of TfR1 staining from different kidney tissue types; top row: normal kidney (left), ccRCC (middle), pRCC (right); bottom row: chRCC (left), oncocytoma (middle), metastatic ccRCC (right). ${ }^{*}, \mathrm{p}<0.05 ;{ }^{* *}, \mathrm{p}<0.01 ;{ }^{* * *}, \mathrm{p}<0.001$. 
Table 2: Association between primary tumor TfR1 level and renal cell tumor patient clinical features

\begin{tabular}{|c|c|c|c|c|c|c|}
\hline \multirow{3}{*}{ Age, years } & \multicolumn{2}{|c|}{ All Patients } & \multicolumn{2}{|c|}{ ccRCC Patients } & \multicolumn{2}{|c|}{ Non-ccRCC patients } \\
\hline & \multirow[t]{2}{*}{$\begin{array}{c}\text { TfR1 } \\
\text { PTP } \\
\text { (mean/SE) }\end{array}$} & $\begin{array}{c}\text { TfR1 } \\
\text { H-score } \\
\text { (mean/SE) }\end{array}$ & \multirow[t]{2}{*}{$\begin{array}{c}\text { TfR1 } \\
\text { PTP } \\
\text { (mean/SE) }\end{array}$} & $\begin{array}{c}\text { TfR1 } \\
\text { H-score } \\
\text { (mean/SE) }\end{array}$ & \multirow[t]{2}{*}{$\begin{array}{c}\text { TfR1 } \\
\text { PTP } \\
\text { (mean/SE) }\end{array}$} & $\begin{array}{c}\text { TfR1 } \\
\text { H-score } \\
\text { (mean/SE) }\end{array}$ \\
\hline & & & & & & \\
\hline$<=60$ & $33.2 / 3.1$ & $70.5 / 7.6$ & $26.4 / 3.3$ & $54.8 / 8.1$ & $60.5 / 7.3$ & $136.3 / 19.5$ \\
\hline$>60$ & $27.8 / 2.9$ & $55.9 / 6.8$ & $21.0 / 3.0$ & $44.1 / 7.5$ & $41.3 / 7.6$ & $95.7 / 21.1$ \\
\hline P-value & 0.44 & 0.48 & 0.52 & 0.69 & 0.095 & 0.13 \\
\hline \multicolumn{7}{|l|}{ Gender } \\
\hline Male & $32.7 / 2.8$ & $67.5 / 6.7$ & $26.6 / 3.0$ & $55.4 / 7.4$ & $51.5 / 7.0$ & $121.8 / 18.6$ \\
\hline Female & $27.5 / 3.4$ & $57.6 / 8.1$ & $19.7 / 3.4$ & $41.2 / 8.4$ & $54.0 / 9.1$ & $113.9 / 23.7$ \\
\hline P-value & 0.34 & 0.37 & 0.34 & 0.31 & 0.87 & 0.88 \\
\hline \multicolumn{7}{|l|}{ Race } \\
\hline White & $30.9 / 2.2$ & $64.4 / 5.4$ & $24.6 / 2.3$ & $51.3 / 5.7$ & $55.3 / 6.1$ & $128 / 16.4$ \\
\hline Black & $30 / 8.6$ & $56.6 / 17.4$ & $4.22 / 3.5$ & $5.11 / 3.7$ & $38.4 / 11.8$ & $76.7 / 26.9$ \\
\hline P-value & 0.40 & 0.40 & 0.22 & 0.22 & 0.33 & 0.29 \\
\hline \multicolumn{7}{|c|}{$\begin{array}{l}\text { Body Mass Index, kg/ } \\
\mathrm{m}^{2}\end{array}$} \\
\hline$<30$ & $34 / 3.3$ & $72.3 / 8.3$ & $30 / 3.7$ & $66.8 / 9.7$ & $45.7 / 8.0$ & $97.6 / 20.3$ \\
\hline$>=30$ & $25.5 / 3.2$ & $50.2 / 7.3$ & $16.5 / 2.9$ & $29.8 / 6.2$ & $59.3 / 9.0$ & $144.8 / 25.0 / 17$ \\
\hline P-value & 0.052 & 0.031 & 0.011 & 0.006 & 0.19 & 0.18 \\
\hline \multicolumn{7}{|c|}{ Smoking History } \\
\hline Never & $28.9 / 3.2$ & $58 / 7.6$ & $22 / 2.3$ & $44.3 / 8.2$ & $54.7 / 8.1$ & $121.7 / 21.2$ \\
\hline Any & $33 / 3.0$ & $70 / 7.2$ & $26.6 / 3.2$ & $56.7 / 7.9$ & $50.2 / 7.9$ & $116.5 / 20.3$ \\
\hline P-value & 0.13 & 0.076 & 0.071 & 0.053 & 0.58 & 0.85 \\
\hline \multicolumn{7}{|l|}{ Pack Years } \\
\hline 0 & $28.9 / 3.2$ & $58 / 7.6$ & $22 / 2.3$ & $44.3 / 8.2$ & $54.7 / 7.6$ & $121.7 / 21.2$ \\
\hline$<=30$ & $30.1 / 4.6$ & $64.7 / 11.1$ & $26 / 4.9$ & $58.4 / 12.5$ & $42.0 / 13.0$ & $91 / 30.7$ \\
\hline$>30$ & $33.3 / 5.0$ & $70.1 / 12.7$ & $28.3 / 5.4$ & $59.7 / 13.6$ & $55.0 / 11.6$ & $121.4 / 36.5$ \\
\hline P-value & 0.34 & 0.21 & 0.12 & 0.082 & 0.54 & 0.42 \\
\hline \multicolumn{7}{|c|}{ Iron Supplement Medication } \\
\hline No & $28.3 / 2.4$ & $57.6 / 5.7$ & $21.2 / 2.4$ & $43.7 / 6.0$ & $49.9 / 6.4$ & $113.7 / 17.2$ \\
\hline Yes & $51.8 / 10.0$ & $116 / 25.5$ & $48.3 / 12.9$ & $103.5 / 32.2$ & $62.5 / 9.2$ & $170.8 / 17.5$ \\
\hline P-value & 0.038 & 0.022 & 0.048 & 0.005 & 0.57 & 0.41 \\
\hline \multicolumn{7}{|l|}{ Anemia } \\
\hline No & $23.7 / 3.1$ & $41.8 / 6.0$ & $14 / 2.4$ & $24.8 / 4.8$ & $43.8 / 8.0$ & $\begin{array}{l}89.5 / 19.5 \\
\text { (Continued) }\end{array}$ \\
\hline
\end{tabular}




\begin{tabular}{|c|c|c|c|c|c|c|}
\hline & \multicolumn{2}{|c|}{ All Patients } & \multicolumn{2}{|c|}{ ccRCC Patients } & \multicolumn{2}{|c|}{ Non-ccRCC patients } \\
\hline & $\begin{array}{c}\text { TfR1 } \\
\text { PTP } \\
\text { (mean/SE) }\end{array}$ & $\begin{array}{c}\text { TfR1 } \\
\text { H-score } \\
\text { (mean/SE) }\end{array}$ & $\begin{array}{c}\text { TfR1 } \\
\text { PTP } \\
\text { (mean/SE) }\end{array}$ & $\begin{array}{c}\text { TfR1 } \\
\text { H-score } \\
\text { (mean/SE) }\end{array}$ & $\begin{array}{c}\text { TfR1 } \\
\text { PTP } \\
\text { (mean/SE) }\end{array}$ & $\begin{array}{c}\text { TfR1 } \\
\text { H-score } \\
\text { (mean/SE) }\end{array}$ \\
\hline Yes & $44.1 / 5.3$ & $101 / 13.9$ & $37.6 / 6.2$ & $86.7 / 16.5$ & $65.4 / 9.7$ & $162.1 / 27.0$ \\
\hline P-value & 0.003 & 0.001 & 0.008 & 0.008 & 0.088 & 0.03 \\
\hline \multicolumn{7}{|c|}{ Iron-Deficient Anemia } \\
\hline No & $27.9 / 3.0$ & $53.5 / 6.7$ & $17.9 / 2.9$ & $35.1 / 6.9$ & $47.6 / 6.7$ & $102.3 / 16.8$ \\
\hline Yes & $73.5 / 10.8$ & $184.1 / 30.6$ & $69.7 / 12.5$ & $175.0 / 35.3$ & $94.2 / 2.5$ & $234.2 / 42.5$ \\
\hline P-value & $<.001$ & $<.001$ & 0.001 & 0.001 & 0.078 & 0.052 \\
\hline \multicolumn{7}{|c|}{ Hemoglobin, g/dL } \\
\hline$<13.3$ & $41.1 / 4.8$ & $92.6 / 12.3$ & $34.8 / 5.5$ & $79.6 / 14.5$ & $57.4 / 9.9$ & $140.5 / 27.3$ \\
\hline$>=13.3$ & $23.6 / 3.3$ & $40.8 / 6.2$ & $13.2 / 2.5$ & $22.4 / 4.5$ & $48.4 / 8.3$ & $100 / 20.6$ \\
\hline P-value & 0.010 & 0.006 & 0.018 & 0.021 & 0.44 & 0.22 \\
\hline \multicolumn{7}{|c|}{ Hypertension } \\
\hline No & $27.7 / 4.1$ & $53.5 / 9.3$ & $21.3 / 4.1$ & $38.1 / 9.0$ & $55.2 / 9.6$ & $132.6 / 26.1$ \\
\hline Yes & $30.3 / 3.0$ & $64.4 / 7.4$ & $23.5 / 3.1$ & $51.9 / 8.3$ & $46.3 / 7.8$ & $104.6 / 21.1$ \\
\hline P-value & 0.82 & 0.65 & 0.99 & 0.80 & 0.43 & 0.41 \\
\hline \multicolumn{7}{|c|}{ Presence of metastasis } \\
\hline No & $28.1 / 2.4$ & $56.8 / 5.4$ & $18.7 / 2.3$ & $37.4 / 5.4$ & $52.8 / 5.8$ & $118.9 / 15.4$ \\
\hline Yes & $42.7 / 4.9$ & $95.5 / 10.0$ & $45.4 / 5.5$ & $101.3 / 15.8$ & $46.1 / 14.9$ & $120.6 / 44.5$ \\
\hline P-value & $<.001$ & $<.001$ & $<.001$ & $<.001$ & 0.72 & 0.86 \\
\hline
\end{tabular}

kidney TfR1 levels (Table 4), in contrast to significant increases in primary tumor TfR1 levels (Table 2). In addition, TfR1 decreases in benign kidney correlated with a history of hypertension. Also opposite of observations in primary tumors, TfR 1 expression in benign kidney was significantly reduced with RCC tumor progression (Figure 5 , Supplementary Figure 3), based on size $(\mathrm{p}<0.001)$, grade $(p<0.001)$, stage $(p<0.001)$, sarcomatoid presence $(p<0.001)$ and sarcomatoid percentage $(p<0.001)$. Similar findings were observed whether or not benign oncocytoma patients were included in analyses (data not shown). Similar associations were also observed for the ccRCC subtype and to a lesser degree (tumor stage only) for non-ccRCC subtypes (Figure 5).

\section{Association of benign kidney TfR1 levels with RCC patient survival}

In survival analyses, lower TfR 1 expression in benign kidney tissue of ccRCC patients was associated with a significantly shorter time to metastasis $(p<0.001)$, cancerspecific death $(p<0.001)$ and death due to any cause $(p<0.001)$ (Figure 6A, Table 5). Significant associations with survival outcomes were similarly observed in non-ccRCC patients (Figure 6B, Table 5). In multivariable analyses adjusting for tumor pathology (and also for age in overall survival analyses), lower TfR1 levels in benign kidney remained independently associated with worse cancer-specific and overall survival among ccRCC patients (Table 5). Similar multivariable analyses were not performed among non-ccRCC patients due to an inadequate number of metastasis/death events.

\section{TfR1 expression in ccRCC and benign renal epithelial cell lines}

We next sought to evaluate TfR 1 expression in a panel of benign renal and ccRCC cell lines cultured under iron-replete conditions. Analysis of TFRC gene expression indicated generally higher transcript levels in ccRCC cell lines than benign renal cell lines (Figure 7A). Western blot demonstrated higher TfR1 protein expression in three of the four ccRCC cell lines compared to benign renal cell lines (Figure 7B). Imaging flow cytometry performed to quantitatively evaluate TfR1 localization confirmed a mixture of cytoplasmic and membranous expression. Furthermore, ccRCC cell lines tended to express higher levels of TfR 1 in the whole cell and in the cytoplasm compared to benign renal cell lines (Figure 7C, 7E). Abundant punctate foci/clusters of TfR1 staining were visualized in both the cytoplasmic 

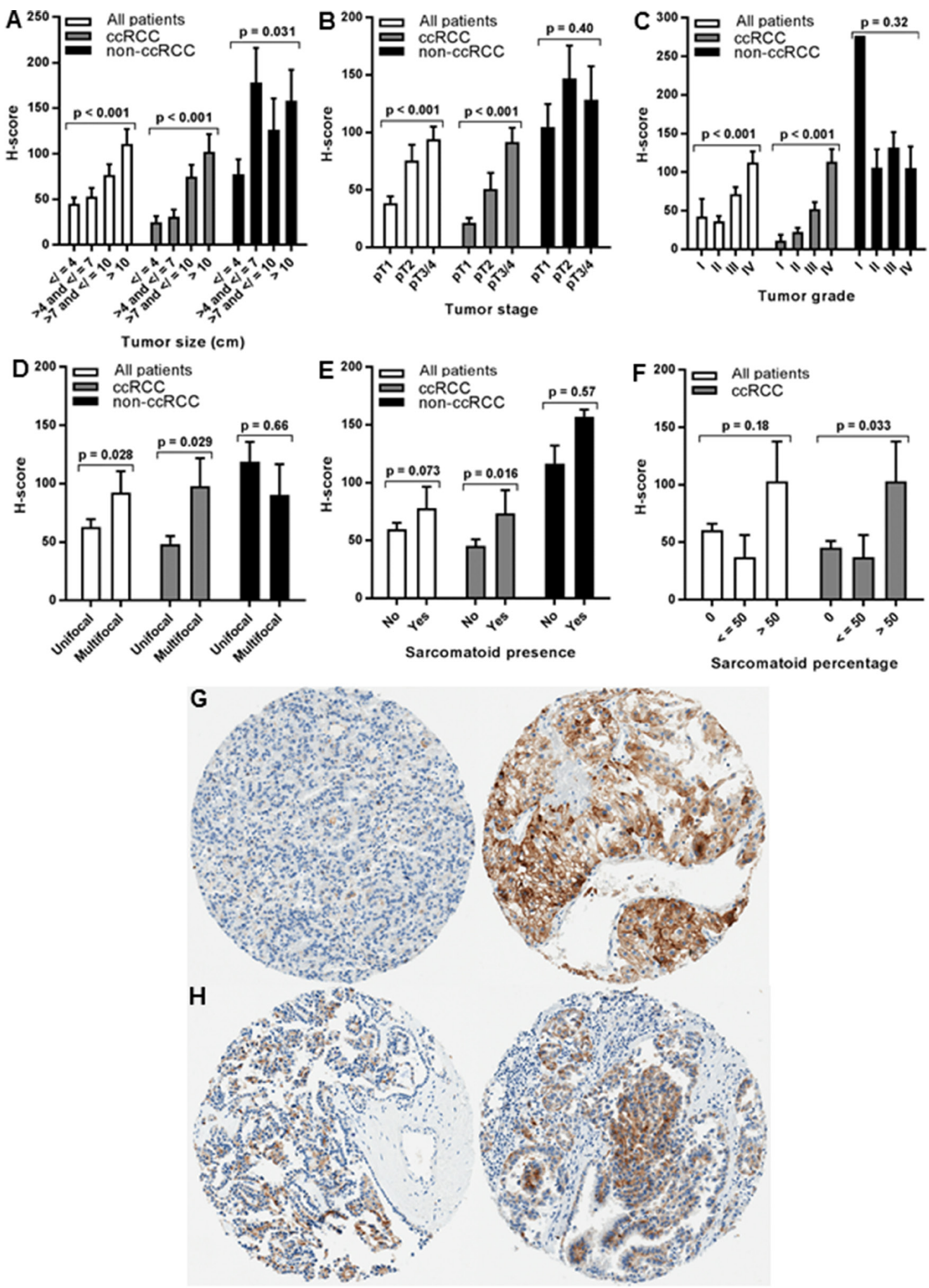

Figure 3: Association of primary tumor TfR1 H-score with renal cell tumor pathology. Primary tumor TfR1 level (H-score) was measured by IHC using renal cell tumor patient TMAs and tested for association with pathologic features of primary tumors, including (A) tumor size (largest diameter), (B) tumor stage, (C) tumor grade, (D) tumor number (focality), (E) presence of sarcomatoid dedifferentiation, and (F) tumor percentage of sarcomatoid dedifferentiation. Only 1 grade I primary tumor was available for the non-ccRCC subset (C), and tumor percentages for two non-ccRCC patients with sarcomatoid dedifferentiation were unknown (F). Representative tissue core images of low grade/stage (left) and high grade/stage (right) primary tumors are shown from $(\mathbf{G})$ ccRCC and $(\mathbf{H})$ pRCCpatients. 
Table 3: Association between primary tumor TfR1 level and RCC patient survival outcomes

\begin{tabular}{|c|c|c|c|c|c|c|c|c|c|c|c|c|c|}
\hline \multirow{2}{*}{\multicolumn{2}{|c|}{$\begin{array}{l}\text { TfR1 protein level } \\
\text { (PTP or H-score) }\end{array}$}} & \multicolumn{4}{|c|}{ Metastasis } & \multicolumn{4}{|c|}{ Cancer-Specific Mortality } & \multicolumn{4}{|c|}{ All-Cause Mortality } \\
\hline & & \multicolumn{2}{|c|}{ Univariate } & \multicolumn{2}{|c|}{ Multivariable } & \multicolumn{2}{|c|}{ Univariate } & \multicolumn{2}{|c|}{ Multivariable } & \multicolumn{2}{|c|}{ Univariate } & \multicolumn{2}{|c|}{ Multivariable } \\
\hline & & $\begin{array}{c}\text { HR } \\
(95 \% \mathrm{CI})\end{array}$ & P-value & $\begin{array}{c}\text { HR } \\
(95 \% \mathrm{CI})\end{array}$ & P-value & $\begin{array}{c}\text { HR } \\
(95 \% \mathrm{CI})\end{array}$ & P-value & $\begin{array}{c}\text { HR } \\
(95 \% \mathrm{CI})\end{array}$ & P-value & $\begin{array}{c}\text { HR } \\
(95 \% \mathrm{CI})\end{array}$ & P-value & $\begin{array}{c}\text { HR } \\
(95 \% \mathrm{CI})\end{array}$ & P-value \\
\hline \multirow{2}{*}{$\mathrm{ccRCC}$} & PTP & $3.44(2.11,5.59)$ & $<.001$ & $1.53(0.87,2.69)$ & 0.14 & $4.51(2.48,8.20)$ & $<.001$ & $1.79(0.93,3.43)$ & 0.080 & $2.71(1.77,4.17)$ & $<.001$ & $1.52(0.95,2.43)$ & 0.080 \\
\hline & H-score & $3.63(2.19,6.00)$ & $<.001$ & $1.82(1.03,3.21)$ & 0.041 & $4.47(2.42,8.24)$ & $<.001$ & $1.90(0.99,3.67)$ & 0.055 & $2.69(1.74,4.15)$ & $<.001$ & $1.61(1.00,2.59)$ & 0.048 \\
\hline \multirow{2}{*}{ Non-ccRCC } & PTP & $1.94(0.49,7.65)$ & 0.28 & NP & $\mathrm{NP}$ & $2.61(0.53,12.90)$ & 0.17 & $\mathrm{NP}$ & NP & $0.95(0.34,2.65)$ & 0.91 & $\mathrm{NP}$ & NP \\
\hline & H-score & $2.16(0.55,8.52)$ & 0.22 & NP & $\mathrm{NP}$ & $4.60(0.69,30.73)$ & 0.049 & NP & NP & $1.69(0.60,4.76)$ & 0.29 & NP & NP \\
\hline
\end{tabular}

Hazard ratios (HR) refer to TfR1 levels above the median. $\mathrm{NP}=$ not performed.

and membranous compartments of all cell lines, and were of significantly higher staining intensity in ccRCC cell lines compared to benign cell lines (Figure 7D, 7E).

\section{DISCUSSION}

Iron has long been implicated in carcinogenesis, although its importance and precise role remain poorly understood. Alterations in iron uptake may play a unique role in RCC, since this cancer is often defined by a dysregulated VHL/HIF- $\alpha$ pathway that governs intracellular iron levels. Consistent with this hypothesis, occupations in the iron/steel industry and medical conditions at risk for systemic iron overload are each reported to have elevated rates of RCC diagnosis [31, 32, 52-54]. Furthermore, chronic systemic iron administration to rodents causes renal tumorigenesis that mimics key features of human RCC. Yet despite these compelling observations, the role of iron uptake in human $\mathrm{RCC}$ has received scarce investigation to date.

$\mathrm{TfR} 1$ is the primary receptor mediating intracellular iron uptake, and characterization of its expression during RCC tumorigenesis and progression is therefore fundamental to understanding the role of iron metabolism in this cancer. Interestingly, polymorphisms have been identified within miRNA binding sites of the human TfR1 gene, TFRC, that increase the risk of RCC [55]. However, TfR1 expression levels in RCC patients have remained unclear. Most RCC tumors, particularly ccRCC,
A

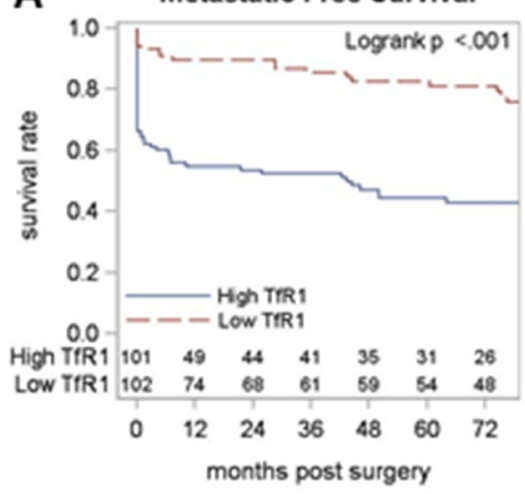

B

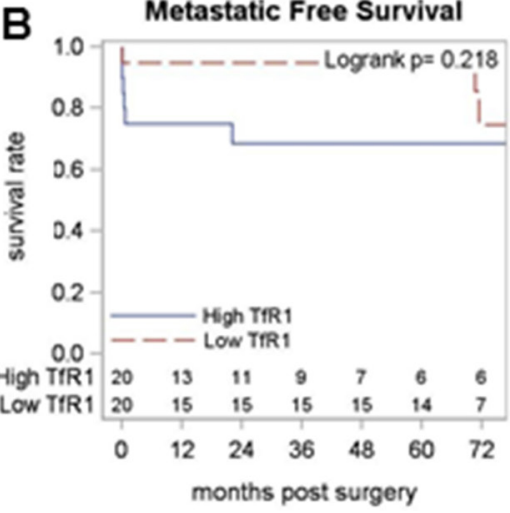

Cancer Specific Survival

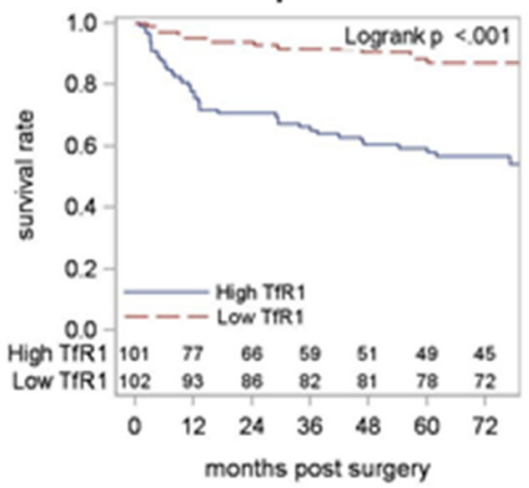

Cancer Specific Survival

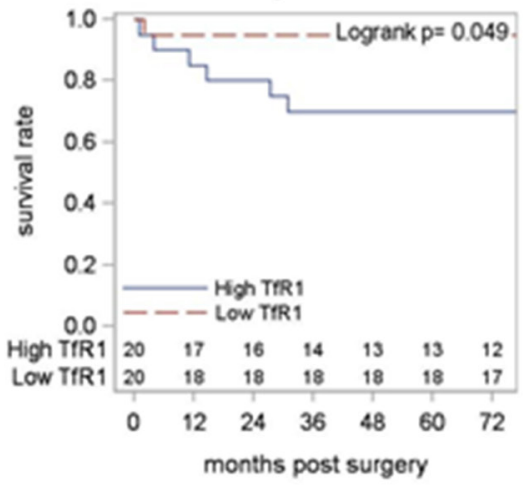

Overall Survival
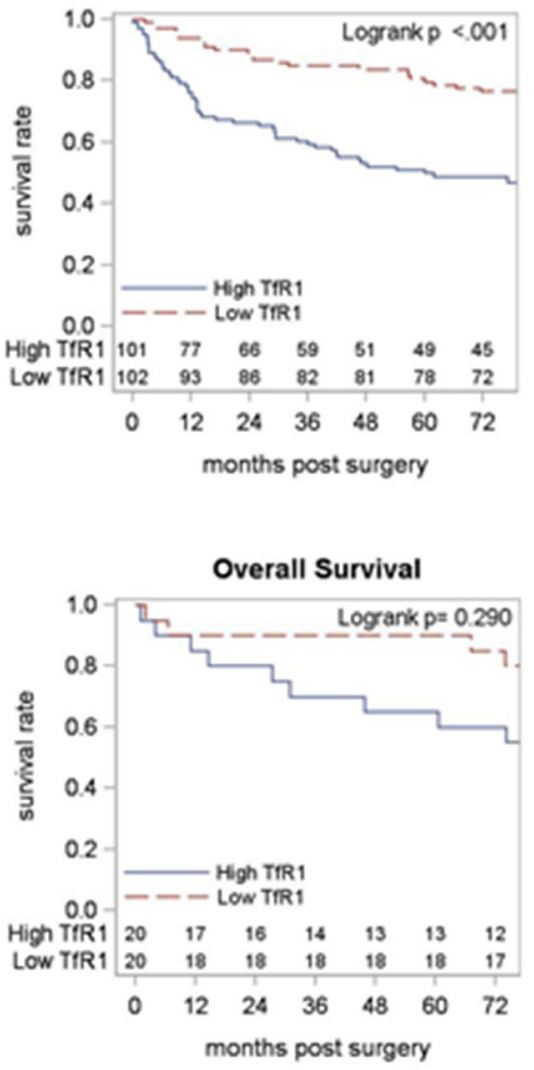

Figure 4: Association of primary tumor TfR1 levels with RCC patient survival. TfR1 level (H-score) measured by IHC in RCC primary tumors was dichotomized at the median for (A) ccRCC and (B) non-ccRCC patient subsets and tested for association with (left to right) metastasis-free survival, cancer-specific survival and overall survival, using Kaplan-Meier methodology. 
Table 4: Association between benign renal epithelial TfR1 level and renal cell tumor patient clinical features

\begin{tabular}{|c|c|c|c|c|c|c|}
\hline & \multicolumn{2}{|c|}{ All Patients } & \multicolumn{2}{|c|}{ ccRCC Patients } & \multicolumn{2}{|c|}{ Non-ccRCC patients } \\
\hline & $\begin{array}{c}\text { TfR1 } \\
\text { PTP } \\
\text { (mean/SE) }\end{array}$ & $\begin{array}{c}\text { TfR1 } \\
\text { H-score } \\
\text { (mean/SE) }\end{array}$ & $\begin{array}{c}\text { TfR1 } \\
\text { PTP } \\
\text { (mean/SE) }\end{array}$ & $\begin{array}{c}\text { TfR1 } \\
\text { H-score } \\
\text { (mean/SE) }\end{array}$ & $\begin{array}{c}\text { TfR1 } \\
\text { PTP } \\
\text { (mean/SE) }\end{array}$ & $\begin{array}{c}\text { TfR1 } \\
\text { H-score } \\
\text { (mean/SE) }\end{array}$ \\
\hline \multicolumn{7}{|l|}{ Age, years } \\
\hline$<=60$ & $46.6 / 1.7$ & $124.8 / 4.8$ & $47.7 / 2.0$ & $127.5 / 5.7$ & $47.0 / 3.0$ & $128.7 / 9.9$ \\
\hline$>60$ & $46.8 / 1.6$ & $125.8 / 4.5$ & $44.6 / 1.9$ & $119.6 / 5.2$ & $51.4 / 4$ & $134.8 / 10.2$ \\
\hline P-value & 0.95 & 0.89 & 0.15 & 0.14 & 0.20 & 0.37 \\
\hline \multicolumn{7}{|l|}{ Gender } \\
\hline Male & $46.0 / 1.4$ & $124.2 / 3.9$ & $45.0 / 1.6$ & $121.2 / 4.7$ & $50.0 / 2.6$ & $134.2 / 6.7$ \\
\hline Female & $48.0 / 2.1$ & $127.1 / 6.0$ & $48.4 / 2.5$ & $128.1 / 6.8$ & $47.8 / 5.3$ & $126.8 / 16.2$ \\
\hline P-value & 0.42 & 0.55 & 0.27 & 0.32 & 0.93 & 0.77 \\
\hline \multicolumn{7}{|l|}{ Race } \\
\hline White & $46.5 / 1.2$ & $124.7 / 3.4$ & $46.0 / 1.4$ & $123.1 / 4.0$ & $48.6 / 2.5$ & $131.1 / 6.7$ \\
\hline Black & $49.8 / 4.2$ & $133.4 / 13.1$ & $52.3 / 5.5$ & $145.7 / 17.2$ & $51.2 / 8.5$ & $133.7 / 26.6$ \\
\hline P-value & 0.65 & 0.80 & 0.45 & 0.30 & 0.47 & 0.73 \\
\hline \multicolumn{7}{|c|}{$\begin{array}{l}\text { Body Mass Index, } \\
\mathrm{kg} / \mathrm{m}^{2}\end{array}$} \\
\hline$<30$ & $45.8 / 1.7$ & $124.7 / 4.9$ & $44.3 / 1.9$ & $120.9 / 5.6$ & $50.2 / 3.5$ & $132.6 / 10.0$ \\
\hline$>=30$ & $48.0 / 1.8$ & $128.1 / 5.1$ & $47.9 / 2.1$ & $127.0 / 5.7$ & $45.1 / 3.8$ & $123.1 / 11.2$ \\
\hline P-value & 0.38 & 0.48 & 0.19 & 0.29 & 0.25 & 0.32 \\
\hline \multicolumn{7}{|c|}{ Smoking History } \\
\hline Never & $47.3 / 1.8$ & $127.8 / 5.3$ & $45.9 / 2.3$ & $123.0 / 6.4$ & $49.9 / 3.4$ & $138.8 / 10.0$ \\
\hline Any & $45.9 / 1.6$ & $122.4 / 4.4$ & $46.2 / 1.8$ & $123.4 / 5.0$ & $48.3 / 3.6$ & $124.3 / 9.8$ \\
\hline P-value & 0.19 & 0.17 & 0.64 & 0.64 & 0.68 & 0.29 \\
\hline \multicolumn{7}{|l|}{ Pack Years } \\
\hline 0 & $47.3 / 1.8$ & $127.8 / 5.3$ & $45.9 / 2.3$ & $123.0 / 6.4$ & $49.9 / 3.4$ & $138.8 / 10.0$ \\
\hline$<=30$ & $48.8 / 2.5$ & $129.0 / 6.9$ & $48.4 / 3.0$ & $128.8 / 8.4$ & $53.3 / 4.0$ & $137.0 / 11.5$ \\
\hline$>30$ & $39.5 / 2.8$ & 106.9/7.9 & $39.4 / 2.9$ & $106.6 / 8.2$ & $29.3 / 5.2$ & $75.5 / 16.5$ \\
\hline P-value & 0.011 & 0.023 & 0.068 & 0.11 & 0.018 & 0.027 \\
\hline \multicolumn{7}{|c|}{$\begin{array}{l}\text { Iron Supplement } \\
\text { Medication }\end{array}$} \\
\hline No & $46.6 / 1.3$ & $125.3 / 3.7$ & $45.5 / 1.5$ & $121.6 / 4.3$ & $48.3 / 2.5$ & $129.9 / 7.2$ \\
\hline Yes & $44.2 / 4.0$ & $113.6 / 11.3$ & $45.2 / 3.3$ & $115.2 / 7.8$ & $41.7 / 14.0$ & $109.4 / 42.1$ \\
\hline P-value & 0.52 & 0.28 & 0.81 & 0.47 & 0.58 & 0.58 \\
\hline \multicolumn{7}{|l|}{ Anemia } \\
\hline No & $51.8 / 1.8$ & $140.0 / 4.9$ & $50.8 / 2.3$ & $135.5 / 6.1$ & $52.9 / 3.1$ & $147.0 / 8.9$ \\
\hline Yes & $41.7 / 2.5$ & $110.3 / 7.3$ & $38.6 / 3.0$ & $102.0 / 8.7$ & $48.2 / 3.3$ & $123.9 / 7.6$ \\
\hline P-value & 0.004 & $<.001$ & 0.006 & 0.003 & 0.18 & 0.057 \\
\hline
\end{tabular}

(Continued) 


\begin{tabular}{|c|c|c|c|c|c|c|}
\hline & \multicolumn{2}{|c|}{ All Patients } & \multicolumn{2}{|c|}{ ccRCC Patients } & \multicolumn{2}{|c|}{ Non-ccRCC patients } \\
\hline & $\begin{array}{c}\text { TfR1 } \\
\text { PTP } \\
\text { (mean/SE) }\end{array}$ & $\begin{array}{c}\text { TfR1 } \\
\text { H-score } \\
\text { (mean/SE) }\end{array}$ & $\begin{array}{c}\text { TfR1 } \\
\text { PTP } \\
\text { (mean/SE) }\end{array}$ & $\begin{array}{c}\text { TfR1 } \\
\text { H-score } \\
\text { (mean/SE) }\end{array}$ & $\begin{array}{c}\text { TfR1 } \\
\text { PTP } \\
\text { (mean/SE) }\end{array}$ & $\begin{array}{c}\text { TfR1 } \\
\text { H-score } \\
(\text { mean/SE) }\end{array}$ \\
\hline \multicolumn{7}{|c|}{$\begin{array}{l}\text { Iron-Deficient } \\
\text { Anemia }\end{array}$} \\
\hline No & $50.0 / 1.7$ & $135.1 / 4.7$ & $48.5 / 2.2$ & $129.5 / 5.9$ & $50.9 / 2.4$ & $139.1 / 7.4$ \\
\hline Yes & $44.6 / 5.7$ & $114.7 / 18.6$ & $44.1 / 7.1$ & $112.4 / 22.8$ & $46.7 / 0.0$ & $125.0 / 15.0$ \\
\hline P-value & 0.28 & 0.14 & 0.46 & 0.28 & 0.46 & 0.37 \\
\hline \multicolumn{7}{|c|}{ Hemoglobin, g/dL } \\
\hline$<13.3$ & $44.2 / 2.2$ & $117.6 / 6.6$ & $41.8 / 5.2$ & $110.3 / 15.1$ & $51.0 / 3.3$ & $131.8 / 9.2$ \\
\hline$>=13.3$ & $51.0 / 2.1$ & $138.0 / 5.5$ & $47.0 / 2.1$ & $125.1 / 5.6$ & $50.8 / 3.2$ & $142.7 / 8.9$ \\
\hline P-value & 0.042 & 0.011 & 0.44 & 0.26 & 0.80 & 0.21 \\
\hline \multicolumn{7}{|c|}{ Hypertension } \\
\hline No & $49.9 / 2.3$ & $135.9 / 6.6$ & $40.6 / 2.5$ & $107.7 / 7.5$ & $54.7 / 4.2$ & $49.3 / 12.6$ \\
\hline Yes & $44.6 / 1.6$ & $118.7 / 4.3$ & $50.8 / 2.7$ & $135.2 / 7.0$ & $43.9 / 3.4$ & $117.1 / 9.2$ \\
\hline P-value & 0.041 & 0.015 & 0.021 & 0.009 & 0.084 & 0.044 \\
\hline \multicolumn{7}{|c|}{$\begin{array}{l}\text { Presence of } \\
\text { metastasis }\end{array}$} \\
\hline No & $48.2 / 1.2$ & $130.7 / 3.5$ & $48.5 / 2.7$ & $131.3 / 7.5$ & $50.3 / 2.5$ & $135.6 / 7.0$ \\
\hline Yes & $39.4 / 3.0$ & $98.6 / 8.2$ & $43.7 / 1.8$ & $115.3 / 5.0$ & $36.1 / 9.4$ & $90.6 / 25.9$ \\
\hline P-value & 0.013 & $<.001$ & 0.095 & 0.04 & 0.15 & 0.094 \\
\hline
\end{tabular}

are characterized by accumulation of HIF- $\alpha$ transcription factors that are activators of TfR1 expression [45-47]. HIF- $2 \alpha$ protein can be increased by iron uptake due to an IRE motif within the HIF- $2 \alpha$ transcript [51], and higher HIF- $2 \alpha$ protein levels correlate with ccRCC progression [50]. These observations provide a mechanistic basis for increases in TfR1 protein during RCC progression, particularly for the ccRCC subtype.

The current study investigates TfR 1 expression and its prognostic significance in renal cell tumor patients. Several prior studies in various cancer types have concluded no association between TfR 1 expression and cancer progression [56-60]. In contrast, the current study found TfR 1 protein levels in RCC primary tumors, and particularly the ccRCC subtype, to be strongly associated with adverse RCC pathology, including primary tumor size, stage, grade, number and sarcomatoid dedifferentiation. Significantly higher tumor TfR1 levels were also detected in patients with a lower BMI, smoking history and anemia (particularly iron-deficient anemia and patients on iron supplementation), all clinical features associated with worse RCC patient outcomes [61-64]. Survival analyses confirmed an association between higher ccRCC primary tumor TfR1 levels and shorter times to patient metastasis and mortality, independent of tumor pathology. These findings indicate that higher primary tumor TfR1 levels correlate with more aggressive clinicopathologic features and a worse overall prognosis, particularly for the ccRCC subtype. Relatively high TfR 1 levels detected in this study among several ccRCC cell lines may reflect their origins from advanced primary tumors [65].

While studies of other cancer types have identified higher TfR1 levels in malignant versus benign tissues [66-68], increased expression has typically not correlated with cancer progression [56-60, 68-71]. Hence, TfR1 protein may have a role in ccRCC tumor progression that is largely unique to this cancer type. Although a similar conclusion cannot be reached for non-ccRCC subtypes based on our current data, our finding that higher nonccRCC primary tumor levels of TfR 1 correlated with cancer-specific mortality suggests a similar role as in ccRCC. Larger studies are warranted to more definitively investigate the prognostic significance of TfR 1 expression in individual non-ccRCC subtypes.

The mechanism by which higher primary tumor TfR1 levels might contribute to RCC progression is unclear. Our detection of abundant TfR1 protein 

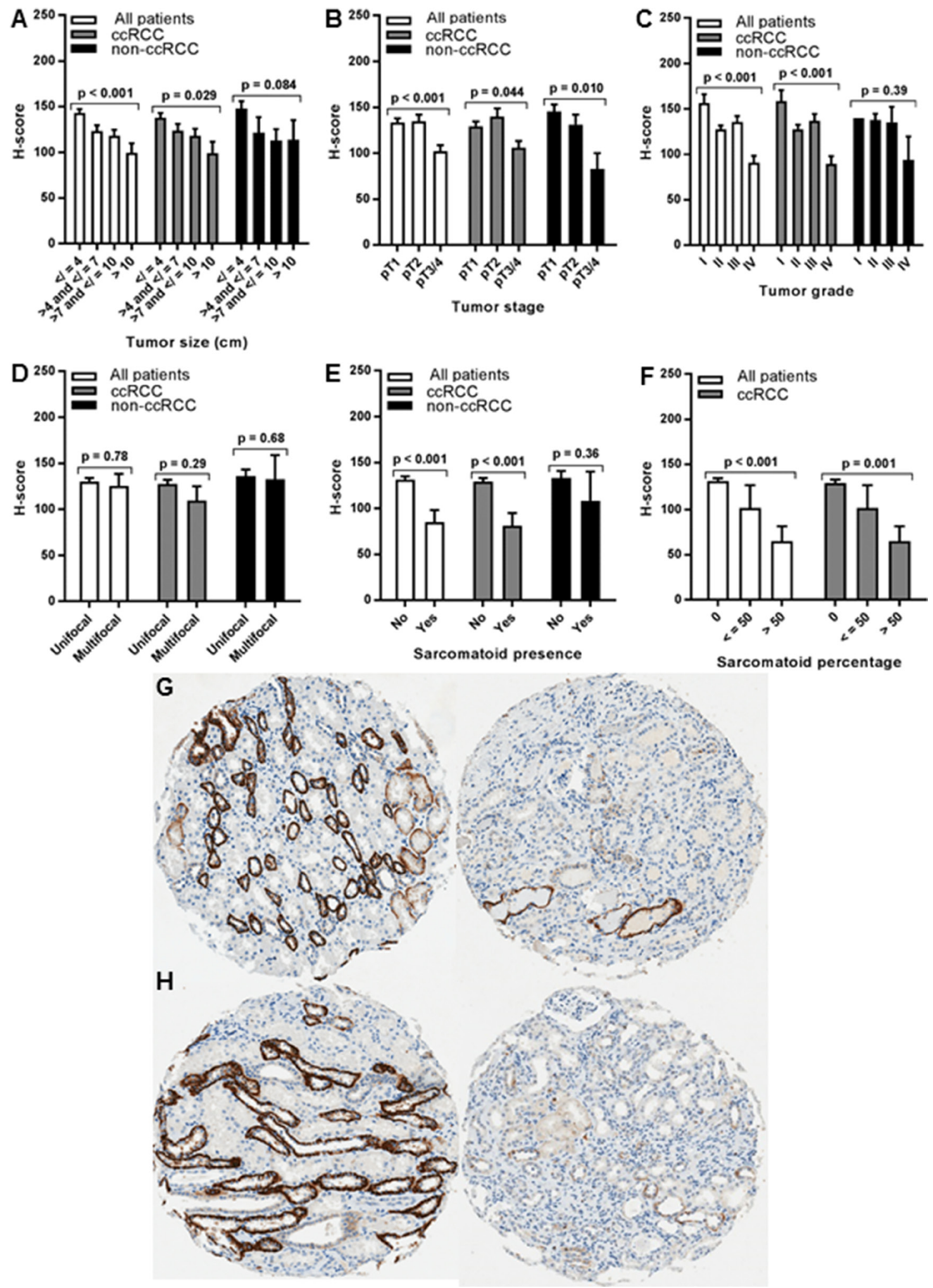

Figure 5: Association of normal kidney TfR1 H-score with RCC tumor pathology. Normal (non-neoplastic) kidney TfR1 level (H-score) was measured by IHC using renal cell tumor patient TMAs and tested for association with pathologic features of renal cell primary tumors, including (A) tumor size (largest diameter), (B) tumor stage, (C) tumor grade, (D) tumor number (focality), (E) presence of sarcomatoid dedifferentiation, and (F) tumor percentage of sarcomatoid dedifferentiation. Only 1 primary tumor in the non-ccRCC subset was grade I (C), and tumor percentages for two non-ccRCC patients with sarcomatoid dedifferentiation were unknown (F). Representative tissue core images of normal kidney tissues are shown from (G) ccRCC and (H) pRCC patients with low grade/stage (left) or high grade/ stage (right) primary tumors. 
Table 5: Association between benign renal epithelial TfR1 protein level and RCC patient survival outcomes

\begin{tabular}{|c|c|c|c|c|c|c|c|c|c|c|c|c|c|}
\hline \multicolumn{2}{|c|}{$\begin{array}{l}\text { TfR1 protein level } \\
\text { (PTP or H-score) }\end{array}$} & \multicolumn{4}{|c|}{ Metastasis } & \multicolumn{4}{|c|}{ Cancer-Specific Mortality } & \multicolumn{4}{|c|}{ All-Cause Mortality } \\
\hline & & \multicolumn{2}{|c|}{ Univariate } & \multicolumn{2}{|c|}{ Multivariable } & \multicolumn{2}{|c|}{ Univariate } & \multicolumn{2}{|c|}{ Multivariable } & \multicolumn{2}{|c|}{ Univariate } & \multicolumn{2}{|c|}{ Multivariable } \\
\hline & & HR $(95 \%$ CI $)$ & P-value & HR $(95 \% \mathrm{CI})$ & P-value & HR $(95 \% \mathrm{CI})$ & P-value & HR (95\% CI) & P-value & HR $(95 \%$ CI $)$ & P-value & HR $(95 \% \mathrm{CI})$ & P-value \\
\hline \multirow{2}{*}{$\mathrm{ccRCC}$} & PTP & $0.48(0.29,0.80)$ & 0.002 & $0.78(0.44,1.37)$ & 0.39 & $0.39(0.22,0.70)$ & $<.001$ & $0.58(0.31,1.10)$ & 0.090 & $0.43(0.27,0.68)$ & $<.001$ & $0.64(0.39,1.05)$ & 0.080 \\
\hline & $\mathrm{H}$-score & $0.36(0.22,0.61)$ & $<.001$ & $0.64(0.36,1.16)$ & 0.14 & $0.30(0.17,0.54)$ & $<.001$ & $0.50(0.26,0.97)$ & 0.039 & $0.32(0.20,0.51)$ & $<.001$ & $0.50(0.30,0.84)$ & 0.009 \\
\hline \multirow{2}{*}{ Non-ccRCC } & РTP & $0.20(0.03,1.29)$ & 0.033 & $\mathrm{NP}$ & $\mathrm{NP}$ & $0.24(0.04,1.64)$ & 0.14 & $\mathrm{NP}$ & NP & $0.20(0.05,0.83)$ & 0.008 & $\mathrm{NP}$ & NP \\
\hline & H-score & $0.07(0.00,1.56)$ & 0.012 & NP & NP & $0.09(0.00,1.89)$ & 0.021 & NP & NP & $0.24(0.06,0.99)$ & 0.021 & NP & NP \\
\hline
\end{tabular}

Hazard ratios (HR) refer to TfR1 levels above the median. NP $=$ not performed.

distributed in clustered foci among ccRCC cell lines might indicate increased trafficking to and/or from the membrane, however additional study is needed. Increased iron uptake as a result of higher TfR 1 activity might promote tumor progression by increasing HIF- $2 \alpha$ protein through IRP1 inactivation [51]. This mechanism would likely require a defective VHL/PHD axis, as is present in ccRCC, since iron uptake otherwise reduces HIF-2 $\alpha$ levels by activating iron-dependent PHD enzymes [3]. Future studies that assess the correlation of HIF- $\alpha$ expression levels with TfR 1 expression levels in
RCC tumors will be helpful to support or challenge this mechanistic model.

Alternatively, TfR1 upregulation and increases in intracellular iron might have a selective advantage for RCC progression due to HIF- $\alpha$-independent mechanisms. The requirement of iron to catalyze DNA repair [21] might be critical for tumor progression, since ccRCC tumors are known to harbor recurrent mutations in several chromatin remodeling/DNA repair genes [4], and the requirement of efficient DNA repair in the setting of such mutations is well described [72]. In addition, the established role of
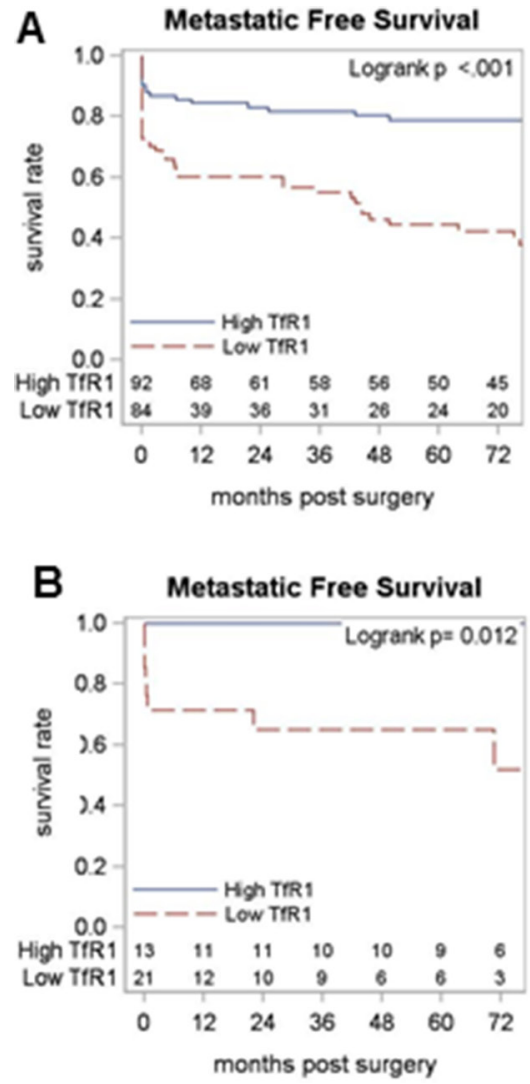
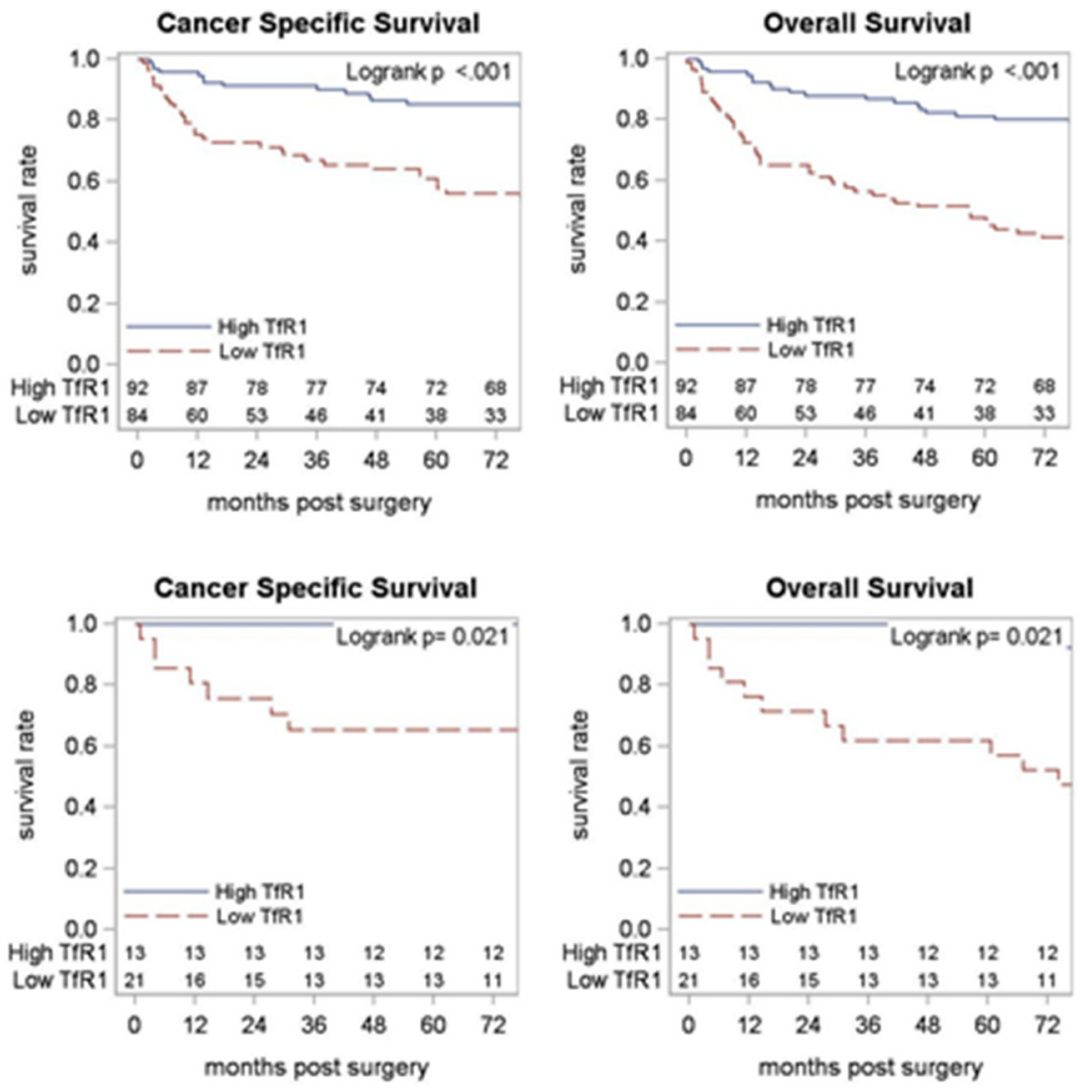

Figure 6: Association of normal kidney TfR1 levels with RCC patient survival. TfR1 level (H-score) measured by IHC in normal (non-neoplastic) kidney tissues from RCC patients was dichotomized at the median for (A) ccRCC and (B) non-ccRCC patient subsets and tested for association with (left to right) metastasic-free survival, cancer-specific survival and overall survival, using KaplanMeier methodology. 


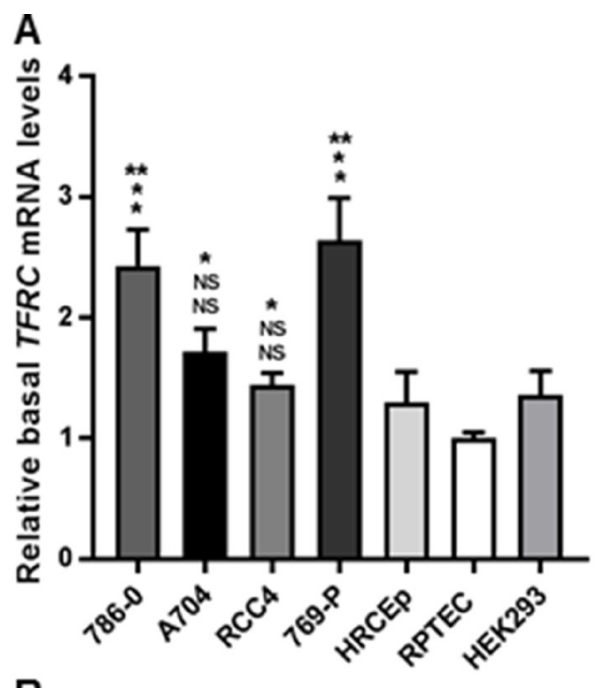

E
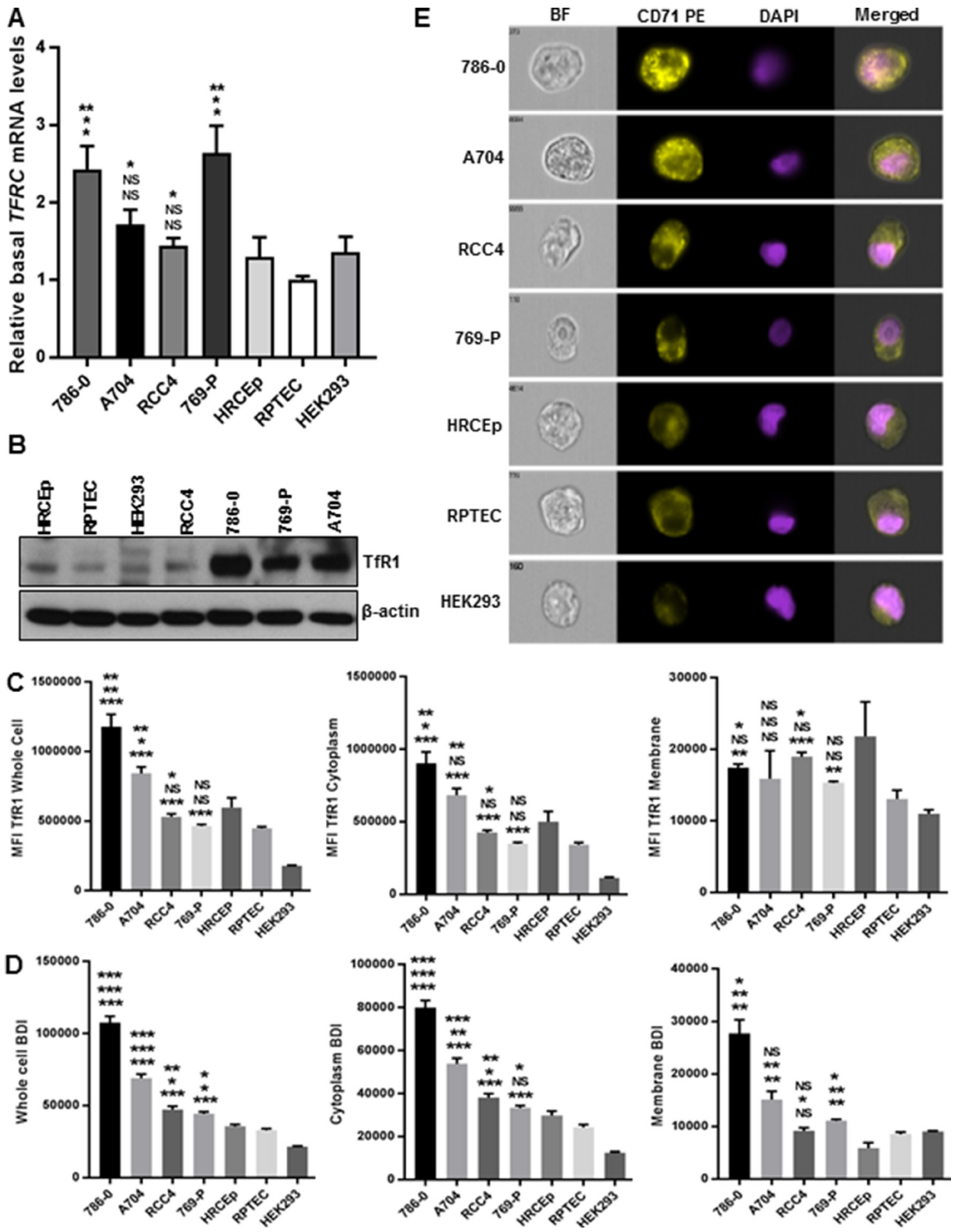

Figure 7: TfR1 expression in ccRCC and benign renal epithelial cell lines. TfR1 expression was compared between benign renal cell lines (RPTEC, HRCEp, HEK293) and ccRCC cell lines (RCC4, 786-0, 769-P, A704) using different approaches. (A) Expression of TFRC mRNA transcript measured using quantitative RT-PCR and normalized to RPTEC. (B) Expression of total TfR1 protein depicted in a representative Western blot. (C) Mean fluorescence intensity (MFI) of TfR1 staining in whole cell vs. cytoplasmic vs. membranous fractions using imaging flow cytometry with morphology-based masking. (D) Bright detail intensity (BDI) of TfR1 staining using imaging flow cytometry with morphologybased masking to specifically measure punctate staining foci/clusters in whole cell vs. cytoplasmic vs. membranous fractions. (E) Representative images of TfR1 staining in ccRCC and benign renal cell lines obtained using imaging flow cytometry. Statistical analysis was performed using a Student's $t$-test. Data are presented as means \pm SEM from at least 3 independent experiments; ${ }^{*}, \mathrm{p}<0.05 ;{ }^{* *}, \mathrm{p}<0.01 ;{ }^{* * *}, \mathrm{p}<0.001 ; \mathrm{NS}=$ nonsignificant for comparison to the RPTEC cell line (top asterisk), HRCEp (middle asterisk) and HEK293 (bottom asterisk). 
iron in oxidative stress induction might also contribute to progression of RCC patient tumors, which harbor recurrent mutations in known redox genes [6, 14-17]. Oxidative stress is known to mediate the carcinogenic effect of iron in the rodent kidneys [73], however its role in tumor progression is unclear. The hypothesis that iron uptake promotes RCC progression through its classic catalytic role in DNA synthesis and cell division is challenged by our finding of highest TfR1 protein levels in chRCC, the most indolent RCC subtype; in addition to relatively high TfR1 levels in benign renal oncocytoma.

Anemia is a common characteristic in advanced RCC patients and typically manifests with low serum iron levels. An alternative explanation for current findings is that higher primary tumor TfR1 protein levels are a compensatory response to lower serum iron levels and IRP1-mediated TfR1 transcript stabilization [39]. Consistent with this explanation, we observed an association between patient anemia and higher tumor TfR1 levels in both ccRCC and non-ccRCC patients. Similarly, Tong et al. has attributed high TfR 1 expression in a pRCC cell line to an intracellular irondeficient state [74]. However, we also observed a decrease (rather than increase) in TfR1 levels in benign kidney tissue of anemic patients, indicating that lower serum iron levels alone cannot account for higher tumor TfR1 levels.

TfR1 may provide a useful therapeutic target for advanced RCC patients. Currently approved clinical therapeutics that target indirectly the VHL/HIF- $\alpha$ axis, which include angiogenesis and mTOR kinase inhibitors, achieve only modest improvements in RCC patient survival [13]. Direct targeting of HIF-2 $\alpha$ is under investigation with promising early results [75], and certain drugs that lower HIF-2 $\alpha$ levels have been suggested to work through reduction of iron levels [47]. Our laboratory and others have shown that iron deprivation can effectively suppress HIF-2 $\alpha$ expression in ccRCC cells in vitro, however no clinical investigation has explored iron uptake targeting in RCC patients to our knowledge $[51,76]$. Encouraging outcomes have been reported in neuroblastoma patients treated with intravenous iron chelation as a chemotherapy adjuvant, and in advanced hepatocellular carcinoma patients as sole therapy [77, 78]. Orally administered iron chelator drugs are now available, but pilot studies in cancer patients have been limited by low grade toxicity [79]. Development of novel approaches to lower iron levels selectively in cancer cells, including by targeting tumor TfR1, holds promise and warrants future study [80].

Two additional findings of interest in the current study are 1) highest TfR1 levels in the non-gravid human body are found in the benign kidney, and 2) decreases in benign kidney TfR1 levels correlate with RCC tumor progression. Regarding the first finding, only placenta, which transports large amounts of Tf to the developing fetus [81], had higher TfR1 levels than kidney among 36 normal body tissues evaluated. Renal TfR 1 expression localized specifically to the tubule epithelium, the presumed site of RCC tumorigenesis. High benign renal TfR1 levels were unexpected since prior studies in other cancer types report minimal TfR 1 expression in matched benign tissues [59, 66, 68, 82]. These results suggest a unique role for iron metabolism in the kidney, as supported by other observations such as the renal specificity of erythropoietin hormone production [25]; the critical role of $\mathrm{Tf}$ for induction of renal tubular and glomerular formation during embryogenesis [83]; and the highest body tissue levels of IRP1 in the rodent kidney [84]. The functional significance of iron uptake into renal tubule epithelium is unclear, but is probably unrelated to cell division because renal epithelium is non-proliferative in the absence of acute renal injury [85]. The polarity of renal tubule TfR1 expression along the basal membrane surface suggests iron is drawn into tubules from adjacent stromal tissue, perhaps for excretion at the luminal epithelial surface into urine. Such a role would be unnecessary to maintain in nonpolarized RCC cells, perhaps explaining lower TfR1 levels in tumors. Given the diversity of potential cellular functions of iron, we suspect that the primary role of iron uptake in benign kidney is distinct from its role in RCC tumors; and that high baseline TfR1 levels in kidneys might simply make the renal epithelium prone to iron overload in situations of high systemic exposure, accounting for the renal specificity of rodent or human cancers in situations/conditions of chronic iron overload $[31,32,52-54]$. Consistent with this hypothesis, systemic administration of iron to rodents leads to detectable iron deposits in only a few organs, namely the kidney, heart and liver [86], each of which demonstrated relatively high TfR1 levels in the present study.

To the best of our knowledge, this report is the first to identify independent prognostic significance of a benign renal tissue protein biomarker for RCC patients. Opposite to increases in primary tumor TfR1 levels during progression, benign renal TfR1 levels decreased in association with adverse clinical prognostic characteristics, RCC tumor progression and patient mortality. The opposite TfR1 alterations in benign kidney and primary tumors during tumor progression might reflect contrasting tissue responses to iron accumulation due to VHL/PHD status. Whereas iron accumulation in VHL-deficient ccRCC tumor cells might increase HIF$2 \alpha$ through IRP1 deactivation and in turn promote TFRC transcription, iron accumulation in VHL wild-type tissues would be expected to decrease HIF-2 $\alpha$ through PHD activation and lead to TFRC downregulation. Whether iron accumulation occurs with RCC tumorigenesis is unknown but it is a well described early event in other renal pathologies [85]. Studies are ongoing in our laboratory to address this question.

Metastatic relapse after nephrectomy for localized disease is estimated to occur in at least $20 \%$ of RCC 
patients [11]. Currently, nephrectomy patient prognosis is estimated based on tumor histopathology, and validated molecular markers that increase the accuracy of prognostication are lacking. Although small, non-invasive RCC tumor patients who undergo partial or radical nephrectomy (tumor stage pT1a) have an outstanding prognosis, many of these patients can be managed conservatively with active surveillance rather than surgery, and most patients undergoing nephrectomy in the contemporary era have more advanced cancers $(\geq p \mathrm{~T} 1 \mathrm{~b})$ for which postoperative recurrence and mortality are frequent [11]. Our results suggest that TfR1 protein in either the primary tumor or benign kidney may provide a novel biomarker for nephrectomy patients with prognostic value independent of primary tumor pathology, particularly for ccRCC patients. Prospective studies are need to determine whether measurement of tumor or kidney levels of TfR 1 in biopsied or surgically resected specimens might assist physicians in postoperative management of nephrectomy patients, including high-risk patient identification for adjuvant therapy trials. Although TfR1 levels in metastasis tissues did not correlate with survival duration in this study, response to individual therapeutic regimens for metastatic disease was not addressed and warrants future investigation.

\section{CONCLUSION}

Although iron has long been implicated in carcinogenesis, its role remains poorly understood. We suspect that iron uptake has a unique role in RCC, given the presence of common alterations in the VHL/ HIF- $\alpha$ pathway that regulates iron levels; in addition to compelling observations from rodent experiments and epidemiologic studies. The current investigation reveals that the primary iron uptake protein, TfR1, has highest body tissue levels in benign kidney, which underscores an important but still uncharacterized role for this protein in renal pathophysiology. Furthermore, alterations in TfR 1 expression in the primary tumor and benign kidney correlate with RCC disease progression and patient mortality. These findings support that iron metabolism may play a critical role in RCC tumorigenesis and progression. In the future it will be critical to elucidate mechanisms of TfR1 regulation and iron metabolism in RCC patients, which may yield novel preventative strategies, biomarkers and targeted therapies for this disease.

\section{MATERIALS AND METHODS}

\section{Patients and tissues}

Institutional review board approval at Roswell Park Cancer Institute (RPCI) was obtained for this study. Informed consent was provided by all patients. A total of 574 paraffin-embedded formalin-fixed tissue specimens (primary renal cell tumor, matched benign kidney and/ or metastasis) were studied from 287 patients who underwent radical or partial nephrectomy $(\mathrm{N}=268)$ and/ or metastatectomy $(\mathrm{N}=74)$ for either $\mathrm{RCC}$ or benign renal oncocytoma between 1995 and 2008 at RPCI, a National Comprehensive Cancer Network institute. Deidentified clinicopathologic and survival data were obtained from a prospectively maintained RPCI nephrectomy patient database and the RPCI cancer patient registry. Primary tumor (T) stage and grade were assigned per updated guidelines of the American Joint Commission on Cancer and the International Society of Pathologists, respectively. Histologic subtype was assigned per recommendations of the World Health Organization criteria and analyzed as either ccRCC or non-ccRCC, the latter of which included pRCC, chRCC, unclassified RCC or rare RCC subtypes. Clinical data delivery and Honest Broker deidentification services were provided by the RPCI Clinical Data Network.

\section{Tissue microarray construction and immunohistochemistry (IHC)}

Three TMAs were constructed from RPCI renal cell tumor patient tissues. Triplicate needle cores of $1.0 \mathrm{~mm}$ diameter were procured from representative areas of each tissue specimen. Each triplicate core was embedded in a separate paraffin block, generating a total of nine paraffin blocks for the three TMAs. Tissue blocks included cores from 14 different non-neoplastic body sites as internal staining controls. A slide section of $4 \mu \mathrm{m}$ thickness was generated for IHC staining. Additionally, a $4 \mu \mathrm{m}$ section from a separate TMA harboring $1.5 \mathrm{~mm}$ normal (benign) tissue cores from 102 different individuals was obtained from US Biomax, Inc (Derwood, MD, USA). A total of 36 different types of normal tissue (2-3 cores each) were represented on this TMA.

TfR1 immunostaining was performed using a Dako Omnis autostainer (Agilent Technologies, Santa Clara, CA, USA). TMA slides were deparaffinized with Clearify and rehydrated using graded alcohols. Target retrieval was performed using Flex TRS High $\mathrm{pH}$ (Agilent Technologies) for 30 minutes. Slides were incubated with mouse anti-human TfR1 antibody (Thermo-Fisher Scientific, Waltham, MA, USA) for 30 minutes at 1:50 dilution. Envision Flex Mouse Linker (Agilent Technologies) secondary antibody was applied for 10 minutes followed by Envision Flex/HRP labeled polymer (Agilent Technologies) for 30 minutes. Dab chromogen was applied for 5 minutes for visualization. Slides were counterstained with Hematoxylin for 8 minutes. TfR1 immunostaining was scored under a clinical genitourinary pathologist $(\mathrm{BX})$ based on PTP score $(0-100 \%)$ and staining intensity $(0+$ absent, $1+$ low, $2+$ moderate, $3+$ high). Each core stain was summarized by a TfR $1 \mathrm{H}$-score, equivalent to the product of the TfR 1 PTP score and the TfR1 intensity score. 


\section{Cell lines}

All cell lines were obtained from the American Type Culture Collection (Rockville, MD, USA), with the exception of the RCC4 cell line which was obtained from the European Collection of Authenticated Cell Cultures General Cell Collection (Salisbury, UK). 786-0, 769-P, A704 and RCC4 cell lines were derived from ccRCC primary renal tumors and harbor known $V H L$ mutations. The human renal cortical epithelium (HRCEp) cell line and renal proximal tubule epithelial cell (RPTEC) line are derived from benign human kidney. The HEK293 cell line is derived from benign human embryonic kidney. All cell lines were maintained in vitro in DMEM media supplemented with L-glutamine (4 mM), sodium pyruvate $(110 \mathrm{mg} / \mathrm{L})$, glucose $(4.5 \mathrm{~g} / \mathrm{L})$ (Corning Cellgro, Manassas, VA, USA), penicillin-streptomycin (100U) (Corning Cellgro) and 10\% fetal bovine serum (Seradigm, Radnor, PA, USA). Cultures were maintained at $37^{\circ} \mathrm{C}$ with $5 \% \mathrm{CO}_{2}$. All cell lines were grown to 60 $80 \%$ confluency prior to assay.

\section{RNA isolation and qPCR}

Total RNA was isolated using a QIAshredder (Qiagen, Germantown, MD, USA) and RNase mini kit (Qiagen). Genomic DNA was digested using DNase I (Qiagen) as described in the on-column DNase digestion protocol from Qiagen. RNA concentration was determined using a Nanodrop 2000c (Thermo-Fisher Scientific). One microgram of RNA was used for reverse transcription using iScript cDNA synthesis kit (Bio-Rad, Hercules, CA, USA) according to the manufacturer's instructions. Quantitative real-time PCR was performed using iTaq Universal SYBR Green Supermix as recommended by the manufacturer (Bio-Rad). The samples were analyzed on a CFX Connect Real-Time PCR Detection system (Bio-Rad) with the following parameters: $10 \mathrm{~min}$ at $95^{\circ} \mathrm{C}, 40$ cycles at $95^{\circ} \mathrm{C}$ for $15 \mathrm{sec}$ and $60^{\circ} \mathrm{C}$ for $1 \mathrm{~min}$. Melting curves were obtained by increasing temperature from $55^{\circ} \mathrm{C}$ to $95^{\circ} \mathrm{C}$ by $0.5^{\circ} \mathrm{C}$ increments. $\Delta \mathrm{Ct}$ was calculated as the difference between the $\mathrm{Ct}$ value for TfR1 and the average of the $\mathrm{Ct}$ values for the B2M and DIMT1 housekeeping genes $(\Delta \mathrm{Ct}$ $=\mathrm{CtTfR} 1-\mathrm{Ct}(\mathrm{B} 2 \mathrm{M}+\mathrm{DIMT} 1) / 2)$, using a threshold cycle limit of 200 RFU. Fold change in expression between TfR1 and the housekeeping genes for each cell line $\left(2^{\Delta \mathrm{Ct}}\right)$ was normalized to the RPTEC cell line. Primers were purchased from Integrated DNA Technologies (IDT, Coralville, IA). Primer sequences included TFRC forward: ACTTGCCCAGATGTTCTCAG; TFRC reverse: GTATC CCTCTAGCCATTCAGTG; $B 2 M$ forward: GGCATTCC TGAAGCTGACAG; $B 2 M$ reverse: TGGATGACGTG AGTAAACCTG; DIMT1 forward: TGATGTAGTGC TGGAAGTTGG, DIMT1 reverse: GTGCCCTGAACT CTTTTGTG.

\section{Western blot}

Cell lines were lysed using RIPA buffer (ThermoFisher Scientific) supplemented with Halt ${ }^{\mathrm{TM}}$ protease inhibitor (Thermo-Fisher Scientific). Cell debris was removed after centrifugation at $4^{\circ} \mathrm{C}$, and total protein concentration was determined using the DC protein assay (Bio-Rad). Electrophoretic separation of protein $(12 \mu \mathrm{g} /$ well) was performed using $4-15 \%$ gradient polyacrylamide gels (Bio-Rad). Separated protein was transferred for 18 hours at $4^{\circ} \mathrm{C}$ onto PVDF membranes (Bio-rad). Membranes were blocked for one hour at room temperature in TBS containing $0.1 \%$ tween (TBS-T) with 5\% fat-free milk, followed by overnight incubation at $4{ }^{\circ} \mathrm{C}$ with mouse anti-human TfR1 antibody (Thermo-Fisher Scientific) (1:500 dilution) or mouse anti-human $\beta$-actin antibody (Cell Signaling Technology, Danvers, MA, USA) (1:10,000 dilution) in 5\% fat-free milk with TBS-T. Membranes were washed in TBS-T and incubated for 30 minutes at room temperature with a 1:2000 dilution of horseradish peroxidase-conjugated rabbit anti-mouse antibody (Cell Signaling Technology) in 5\% milk with TBS-T. Protein signals were developed on X-ray film using the Pierce ECL Western blotting substrate (Thermo-Fisher Scientific) or the SuperSignal West Femto Maximum Sensitive Substrate (Thermo-Fisher Scientific). X-ray film of blots was digitized using an office scanner (Epson, Long Beach, CA, USA).

\section{Imaging flow cytometry}

Cells were harvested using Accutase enzymatic solution (Sigma-Aldrich, St. Louis, MO, USA), washed and resuspended in $200 \mu \mathrm{L}$ FACS buffer (PBS, 5\% FBS, and $0.01 \%$ sodium azide), followed by incubation with $5 \mu \mathrm{L}$ phycoerythrin-conjugated anti-human TfR1 antibody (BioLegend, San Diego, CA, USA) for 20 minutes at room temperature to stain for TfR1 membranous protein. Surface-stained cells were then washed and fixed for 10 minutes in 1 $\mathrm{mL}$ of $4 \%$ Formaldehyde solution (Polysciences, Inc. Warrington, PA, USA), followed by permeabilization for 20 minutes at room temperature using $200 \mu \mathrm{L}$ of $0.01 \%$ Triton $^{\mathrm{TM}} \mathrm{X}-100$ buffer (Sigma Aldrich, St Louis, MO, USA). After fixation/permeabilization, cells were re-incubated with phycoerythrin-conjugated anti-human TfR 1 antibody for 20 minutes at room temperature to stain cytoplasmic TfR 1 protein. Cells were then washed and resuspended into $30 \mu \mathrm{L}$ FACS buffer, to which $10 \mu \mathrm{L}$ DAPI (4',6-Diamidino-2-Phenylindole) (Life Technologies, Carlsbad, CA, USA) at $5 \mu \mathrm{g} / \mathrm{mL}$ was added for 10 minutes for nuclear staining. Sample acquisition was performed using the ImageStream $X^{\mathrm{TM}}$ MKII imaging flow cytometer (Amnis, Seattle, WA, 
USA) with at least 10,000 events recorded per sample using INSPIRE software (Amnis). Sample analysis was conducted using IDEAS software v6.2. Morphologybased masks were created to distinguish between whole cell vs. cytoplasmic vs. membranous fractions of the cells. Mean fluorescence intensity (MFI) was then calculated using the morphology-based masks for the overall expression of TfR1 on these fractions of the cells. The Bright Detail Intensity (BDI) was measured to compute the intensity of localized or clustered TfR 1 protein using an intensity threshold of $\leq 3$ pixels in radius within the masked area for the whole cell, cytoplasm and membrane fractions.

\section{Statistics}

Patient characteristics were summarized as frequencies and relative frequencies, with continuous variables categorized based on either clinically relevant thresholds or dichotomization at the median. TfR 1 immunostain levels (PTP and H-score) were summarized separately for primary tumor tissue, matched benign kidney tissue and metastasis tissue using the mean and standard error (SE) and compared between different tissue types in a pairwise fashion using the Mann-Whitney $U$ test. A Spearman correlation coefficient and paired $t$-test were used to compare immunostain H-score levels between matched primary tumors and metastasis tissues, and between matched primary tumors and benign kidney tissues. Associations between TfR1 immunostain scores and patient clinicopathologic variables were evaluated using either the Mann-Whitney $U$ test or Kruskal Wallis exact test, as appropriate. For survival analyses, TfR1 $\mathrm{H}$-scores were dichotomized at the median for the ccRCC and non-ccRCC subsets and summarized as low (at or below the median) or high (above the median). Univariable association between low vs. high TfR1 scores and survival outcomes was evaluated using Cox regression models and standard Kaplan-Meier methods, with comparisons made using a log-rank test. Multivariable analyses of high vs. low TfR1 scores and survival outcomes were conducted using Cox regression models, adjusting for age (overall survival only), tumor stage, grade, and size. All models were fit using Firth's method and hazard ratios (with corresponding 95\% CI's) were obtained from model estimates. Model assumptions were verified graphically using residual plots. All statistical analyses of TfR1 IHC scores were conducted using SAS v9.4 (Cary, NC, USA). Cell line data were summarized using the mean $\pm \mathrm{SE}$, with comparisons between groups made using a Student's twotailed, unpaired $t$-test with the GraphPad Prism software package v.6.07 (Graphpad Software Inc., San Diego, CA, USA). Cell line gene expression levels determined by RT-PCR were compared by $t$-test comparisons of mean $\Delta \mathrm{Ct}$ values. All statistical analyses were conducted at a significance level of 0.05 .

\section{Abbreviations}

ACO1/IRP1, Iron regulatory protein 1; BDI, Bright detail intensity; BMI, Body mass index; ccRCC, Clear cell RCC; chRCC, Chromophobe RCC; FTH1, Ferritin heavy chain; FTL, Ferritin light chain; HAMP, Hepcidin; HIF- $\alpha$, Hypoxia inducible factor- $\alpha$; HRCEp, Human renal cortical epithelium; IHC, Immunohistochemistry; IRE, Iron responsive element; IREB2/IRP2, Iron regulatory protein 2; MFI, Mean fluorescence intensity; MSI, Maximum staining intensity; NCI, National cancer institute; nonccRCC, non-clear cell renal cell carcinoma; PHD, Proline hydroxylase; pRCC, Papillary RCC; PTP, percentage of tissue positivity; RCC, Renal cell carcinoma; RPCI, Roswell Park Cancer Institute; RPTEC, Renal proximal tubule epithelial cell; SE, Standard error; SLC11A2/ DMT1, Divalent metal transporter 1; SLC40A1/FPN1, Ferroportin; Tf, Transferrin; TfR2, Transferrin receptor 2; TFRC/TfR1/CD71, Transferrin receptor 1; TMA(s), Tissue microarray(s); VHL, von Hippel Lindau.

\section{Author contributions}

Manuscript composition was performed by C.J. Greene and E.C. Kauffman, and editorial support was provided by K. Attwood, N.J. Sharma, K.W. Gross, G.J. Smith and B. Xu. C.J. Greene performed condition optimization for TfR1 IHC and all in vitro experiments including their statistical analyses, with the exception of imaging flow cytometry which was performed and analyzed by N.J. Sharma. B. Xu and C.J. Greene were responsible for IHC scoring. K. Atwood performed all IHC statistical analyses. K.W. Gross and G.J. Smith provided intellectual and technical support. E.C. Kauffman was responsible for project conception and supervised all members of the research team and all experimental aspects.

\section{CONFLICTS OF INTEREST}

The authors declare no conflicts of interest.

\section{FUNDING}

Patient tissue and IHC services were provided by the Pathology Resource Network, a RPCI shared resource which is funded by the National Cancer Institute (NCI) Cancer Center Support Grant grant P30CA016056. Deidentified clinical data was provided by the RPCI Clincal Data Network shared resource, which is supported by NCI grant P30CA16056. IHC statistics were performed by the RPCI Biostatistics shared resource, which is supported by NCI grant P30CA016056. Imaging flow cytometry experiments were assisted by the RPCI Flow Cytometry shared resource, which is supported by NCI grant P30CA016056, the NCI Cancer Research Specialist 
grant R50CA211108, and the Imagestream shared instrument grant 1S10OD018048. Additional funding was provided by the RPCI Alliance Foundation and an American Cancer Society Institutional Research Grant.

\section{REFERENCES}

1. Siegel RL, Miller KD, Jemal A. Cancer Statistics, 2017. CA Cancer J Clin. 2017; 67:7-30.

2. Chow WH, Dong LM, Devesa SS. Epidemiology and risk factors for kidney cancer. Nat Rev Urol. 2010; 7:245-57.

3. Linehan WM, Ricketts CJ. The metabolic basis of kidney cancer. Semin Cancer Biol. 2013; 23:46-55.

4. Creighton CJ, Morgan M, Gunaratne PH, Wheeler DA, Gibbs RA, Gordon Robertson A, Chu A, Beroukhim R, Cibulskis K, Signoretti S, Vandin Hsin-Ta Wu F, Raphael BJ, Verhaak RG, et al, and Cancer Genome Atlas Research Network. Comprehensive molecular characterization of clear cell renal cell carcinoma. Nature. 2013; 499:43-49.

5. Davis CF, Ricketts CJ, Wang M, Yang L, Cherniack AD, Shen H, Buhay C, Kang H, Kim SC, Fahey CC, Hacker KE, Bhanot G, Gordenin DA, et al, and The Cancer Genome Atlas Research Network. The somatic genomic landscape of chromophobe renal cell carcinoma. Cancer Cell. 2014; 26:319-30.

6. Linehan WM, Spellman PT, Ricketts CJ, Creighton CJ, Fei SS, Davis C, Wheeler DA, Murray BA, Schmidt L, Vocke CD, Peto M, Al Mamun AA, Shinbrot E, et al, and Cancer Genome Atlas Research Network. Comprehensive Molecular Characterization of Papillary Renal-Cell Carcinoma. N Engl J Med. 2016; 374:135-45.

7. Patel NH, Attwood KM, Hanzly M, Creighton TT, Mehedint DC, Schwaab T, Kauffman EC. Comparative analysis of smoking as a risk factor among renal cell carcinoma histological subtypes. J Urol. 2015; 194:640-46.

8. Lipworth L, Tarone RE, Lund L, McLaughlin JK. Epidemiologic characteristics and risk factors for renal cell cancer. Clin Epidemiol. 2009; 1:33-43.

9. Gandaglia G, Ravi P, Abdollah F, Abd-El-Barr AE, Becker A, Popa I, Briganti A, Karakiewicz PI, Trinh QD, Jewett MA, Sun M. Contemporary incidence and mortality rates of kidney cancer in the United States. Can Urol Assoc J. 2014; 8:247-52.

10. Sun M, Thuret R, Abdollah F, Lughezzani G, Schmitges J, Tian Z, Shariat SF, Montorsi F, Patard JJ, Perrotte P, Karakiewicz PI. Age-adjusted incidence, mortality, and survival rates of stage-specific renal cell carcinoma in North America: a trend analysis. Eur Urol. 2011; 59:135-41.

11. Williamson TJ, Pearson JR, Ischia J, Bolton DM, Lawrentschuk N. Guideline of guidelines: follow-up after nephrectomy for renal cell carcinoma. BJU Int. 2016; 117:555-62.

12. Choueiri TK, Motzer RJ. Systemic therapy for metastatic renal-cell carcinoma. N Engl J Med. 2017; 376:354-66.
13. Molina AM, Motzer RJ. Clinical practice guidelines for the treatment of metastatic renal cell carcinoma: today and tomorrow. Oncologist. 2011; 16:45-50.

14. Cardaci S, Ciriolo MR. TCA Cycle defects and cancer: when metabolism tunes redox state. Int J Cell Biol. 2012; 2012:161837.

15. Ishii T, Yasuda K, Akatsuka A, Hino O, Hartman PS, Ishii $\mathrm{N}$. A mutation in the SDHC gene of complex II increases oxidative stress, resulting in apoptosis and tumorigenesis. Cancer Res. 2005; 65:203-09.

16. Ooi A, Wong JC, Petillo D, Roossien D, Perrier-Trudova V, Whitten D, Min BW, Tan MH, Zhang Z, Yang XJ, Zhou M, Gardie B, Molinié V, et al. An antioxidant response phenotype shared between hereditary and sporadic type 2 papillary renal cell carcinoma. Cancer Cell. 2011; 20:511-23.

17. Gregg JL, Turner RM 2nd, Chang G, Joshi D, Zhan Y, Chen L, Maranchie JK. NADPH oxidase NOX4 supports renal tumorigenesis by promoting the expression and nuclear accumulation of HIF2 $\alpha$. Cancer Res. 2014; 74:3501-11.

18. Kruszewski M. Labile iron pool: the main determinant of cellular response to oxidative stress. Mutat Res. 2003; 531:81-92.

19. Lipiński P, Drapier JC, Oliveira L, Retmańska H, Sochanowicz B, Kruszewski M. Intracellular iron status as a hallmark of mammalian cell susceptibility to oxidative stress: a study of L5178Y mouse lymphoma cell lines differentially sensitive to $\mathrm{H}(2) \mathrm{O}(2)$. Blood. 2000; 95:2960-66.

20. Toyokuni S. The origin and future of oxidative stress pathology: from the recognition of carcinogenesis as an iron addiction with ferroptosis-resistance to non-thermal plasma therapy. Pathol Int. 2016; 66:245-59.

21. Le NT, Richardson DR. The role of iron in cell cycle progression and the proliferation of neoplastic cells. Biochim Biophys Acta. 2002; 1603:31-46.

22. Johansson C, Tumber A, Che K, Cain P, Nowak R, Gileadi $\mathrm{C}$, Oppermann U. The roles of Jumonji-type oxygenases in human disease. Epigenomics. 2014; 6:89-120.

23. Veatch JR, McMurray MA, Nelson ZW, Gottschling DE. Mitochondrial dysfunction leads to nuclear genome instability via an iron-sulfur cluster defect. Cell. 2009; 137:1247-58.

24. Saxena N, Maio N, Crooks DR, Ricketts CJ, Yang Y, Wei MH, Fan TW, Lane AN, Sourbier C, Singh A, Killian JK, Meltzer PS, Vocke CD, et al. SDHB-Deficient cancers: the role of mutations that impair iron sulfur cluster delivery. $\mathrm{J}$ Natl Cancer Inst. 2016; 108:108.

25. Haase VH. Hypoxic regulation of erythropoiesis and iron metabolism. Am J Physiol Renal Physiol. 2010; 299:F1-13.

26. Li JL, Okada S, Hamazaki S, Ebina Y, Midorikawa O. Subacute nephrotoxicity and induction of renal cell carcinoma in mice treated with ferric nitrilotriacetate. Cancer Res. 1987; 47:1867-69. 
27. Vargas-Olvera CY, Sánchez-González DJ, Solano JD, Aguilar-Alonso FA, Montalvo-Muñoz F, MartínezMartínez CM, Medina-Campos ON, Ibarra-Rubio ME. Characterization of $\mathrm{N}$-diethylnitrosamine-initiated and ferric nitrilotriacetate-promoted renal cell carcinoma experimental model and effect of a tamarind seed extract against acute nephrotoxicity and carcinogenesis. Mol Cell Biochem. 2012; 369:105-17.

28. Ebina Y, Okada S, Hamazaki S, Ogino F, Li JL, Midorikawa O. Nephrotoxicity and renal cell carcinoma after use of iron- and aluminum-nitrilotriacetate complexes in rats. J Natl Cancer Inst. 1986; 76:107-13.

29. Iqbal M, Okazaki Y, Okada S. Curcumin attenuates oxidative damage in animals treated with a renal carcinogen, ferric nitrilotriacetate (Fe-NTA): implications for cancer prevention. Mol Cell Biochem. 2009; 324:157-64.

30. Uemura H, Nakagawa Y, Yoshida K, Saga S, Yoshikawa K, Hirao Y, Oosterwijk E. MN/CA IX/G250 as a potential target for immunotherapy of renal cell carcinomas. Br J Cancer. 1999; 81:741-46.

31. Ricchi P, Ammirabile M, Spasiano A, Costantini S, Di Matola T, Cartenì G, Filosa A, Cinque P. Renal cell carcinoma in adult patients with thalassaemia major: a description of three cases. Br J Haematol. 2014; $165: 887-88$.

32. Seminog OO, Ogunlaja OI, Yeates D, Goldacre MJ. Risk of individual malignant neoplasms in patients with sickle cell disease: english national record linkage study. J R Soc Med. 2016; 109:303-09.

33. Weinberg ED. Tobacco smoke iron: an initiator/promoter of multiple diseases. Biometals. 2009;22:207-10.

34. Alberghini A, Recalcati S, Tacchini L, Santambrogio P, Campanella A, Cairo G. Loss of the von Hippel Lindau tumor suppressor disrupts iron homeostasis in renal carcinoma cells. J Biol Chem. 2005; 280:30120-28.

35. Sourbier C, Srivastava G, Ghosh MC, Ghosh S, Yang Y, Gupta G, Degraff W, Krishna MC, Mitchell JB, Rouault TA, Linehan WM. Targeting HIF $2 \alpha$ translation with Tempol in VHL-deficient clear cell renal cell carcinoma. Oncotarget. 2012; 3:1472-82. https://doi.org/10.18632/oncotarget.561.

36. Heath JL, Weiss JM, Lavau CP, Wechsler DS. Iron deprivation in cancer-potential therapeutic implications. Nutrients. 2013; 5:2836-59.

37. Chua AC, Delima RD, Morgan EH, Herbison CE, TirnitzParker JE, Graham RM, Fleming RE, Britton RS, Bacon BR, Olynyk JK, Trinder D. Iron uptake from plasma transferrin by a transferrin receptor 2 mutant mouse model of haemochromatosis. J Hepatol. 2010; 52:425-31.

38. Silvestri L, Nai A, Pagani A, Camaschella C. The extrahepatic role of TFR2 in iron homeostasis. Front Pharmacol. 2014; 5:93.

39. Kuhn LC. Iron regulatory proteins and their role in controlling iron metabolism. Metallomics. 2015; 7:232-43. https://doi.org/10.1039/C4MT00164H.
40. Gnarra JR, Tory K, Weng Y, Schmidt L, Wei MH, Li H, Latif F, Liu S, Chen F, Duh FM, Lubensky I, Duan DR, Florence C, et al. Mutations of the VHL tumour suppressor gene in renal carcinoma. Nat Genet. 1994; 7:85-90.

41. Hsieh JJ, Chen D, Wang PI, Marker M, Redzematovic A, Chen YB, Selcuklu SD, Weinhold N, Bouvier N, Huberman $\mathrm{KH}$, Bhanot U, Chevinsky MS, Patel P, et al. Genomic biomarkers of a randomized trial comparing first-line everolimus and sunitinib in patients with metastatic renal cell carcinoma. Eur Urol. 2017; 71:405-14.

42. Yang L, Zhao Z, Zhao S, Chen C, Cong X, Li Z, Ren M. The Clinicopathological Significance of Epigenetic Silencing of VHL Promoter and Renal Cell Carcinoma: A Meta-Analysis. Cell Physiol Biochem. 2016; 40:1465-1472. https://doi.org/10.1159/000453198.

43. Moore LE, Nickerson ML, Brennan P, Toro JR, Jaeger E, Rinsky J, Han SS, Zaridze D, Matveev V, Janout V, Kollarova H, Bencko V, Navratilova M, et al. Von HippelLindau (VHL) inactivation in sporadic clear cell renal cancer: associations with germline VHL polymorphisms and etiologic risk factors. PLoS Genet. 2011; 7:e1002312.

44. Gordan JD, Lal P, Dondeti VR, Letrero R, Parekh KN, Oquendo CE, Greenberg RA, Flaherty KT, Rathmell WK, Keith B, Simon MC, Nathanson KL. HIF-alpha effects on c-Myc distinguish two subtypes of sporadic VHL-deficient clear cell renal carcinoma. Cancer Cell. 2008; 14:435-46.

45. Mandriota SJ, Turner KJ, Davies DR, Murray PG, Morgan NV, Sowter HM, Wykoff CC, Maher ER, Harris AL, Ratcliffe PJ, Maxwell PH. HIF activation identifies early lesions in VHL kidneys: evidence for site-specific tumor suppressor function in the nephron. Cancer Cell. 2002; 1:459-68.

46. Tacchini L, Gammella E, De Ponti C, Recalcati S, Cairo G. Role of HIF-1 and NF-kappaB transcription factors in the modulation of transferrin receptor by inflammatory and anti-inflammatory signals. J Biol Chem. 2008; 283:20674-86.

47. Zimmer M, Ebert BL, Neil C, Brenner K, Papaioannou I, Melas A, Tolliday N, Lamb J, Pantopoulos K, Golub T, Iliopoulos O. Small-molecule inhibitors of HIF-2a translation link its 5'UTR iron-responsive element to oxygen sensing. Mol Cell. 2008; 32:838-48.

48. Kondo K, Klco J, Nakamura E, Lechpammer M, Kaelin WG Jr. Inhibition of HIF is necessary for tumor suppression by the von Hippel-Lindau protein. Cancer Cell. 2002; 1:237-46.

49. Maranchie JK, Vasselli JR, Riss J, Bonifacino JS, Linehan WM, Klausner RD. The contribution of VHL substrate binding and HIF1-alpha to the phenotype of VHL loss in renal cell carcinoma. Cancer Cell. 2002; 1:247-55.

50. Kroeger N, Seligson DB, Signoretti S, Yu H, Magyar CE, Huang J, Belldegrun AS, Pantuck AJ. Poor prognosis and advanced clinicopathological features of clear cell renal cell carcinoma (ccRCC) are associated with cytoplasmic 
subcellular localisation of Hypoxia inducible factor- $2 \alpha$. Eur J Cancer. 2014; 50:1531-40.

51. Sanchez M, Galy B, Muckenthaler MU, Hentze MW. Ironregulatory proteins limit hypoxia-inducible factor-2alpha expression in iron deficiency. Nat Struct Mol Biol. 2007; 14:420-26.

52. Mandel JS, McLaughlin JK, Schlehofer B, Mellemgaard A, Helmert U, Lindblad P, McCredie M, Adami HO. International renal-cell cancer study. IV. Occupation. Int J Cancer. 1995; 61:601-5.

53. McCredie M, Stewart JH. Risk factors for kidney cancer in New South Wales. IV. Occupation. Br J Ind Med. 1993; 50:349-54.

54. Partanen T, Heikkilä P, Hernberg S, Kauppinen T, Moneta G, Ojajärvi A. Renal cell cancer and occupational exposure to chemical agents. Scand J Work Environ Health. 1991; 17:231-39.

55. Wei H, Ke HL, Lin J, Shete S, Wood CG, Hildebrandt MA. MicroRNA target site polymorphisms in the VHL-HIF1 $\alpha$ pathway predict renal cell carcinoma risk. Mol Carcinog. 2014; 53:1-7.

56. Nakamaki T, Kawabata H, Saito B, Matsunawa M, Suzuki J, Adachi D, Tomoyasu S, Phillip Koeffler H. Elevated levels of transferrin receptor 2 mRNA, not transferrin receptor $1 \mathrm{mRNA}$, are associated with increased survival in acute myeloid leukaemia. Br J Haematol. 2004; 125:42-49.

57. Kukulj S, Jaganjac M, Boranic M, Krizanac S, Santic Z, Poljak-Blazi M. Altered iron metabolism, inflammation, transferrin receptors, and ferritin expression in non-smallcell lung cancer. Med Oncol. 2010; 27:268-77.

58. Wang B, Zhang J, Song F, Tian M, Shi B, Jiang H, Xu W, Wang H, Zhou M, Pan X, Gu J, Yang S, Jiang L, Li Z. EGFR regulates iron homeostasis to promote cancer growth through redistribution of transferrin receptor 1 . Cancer Lett. 2016; 381:331-40.

59. Brookes MJ, Hughes S, Turner FE, Reynolds G, Sharma N, Ismail T, Berx G, McKie AT, Hotchin N, Anderson GJ, Iqbal T, Tselepis C. Modulation of iron transport proteins in human colorectal carcinogenesis. Gut. 2006; 55:1449-60.

60. Prutki M, Poljak-Blazi M, Jakopovic M, Tomas D, Stipancic I, Zarkovic N. Altered iron metabolism, transferrin receptor 1 and ferritin in patients with colon cancer. Cancer Lett. 2006; 238:188-96.

61. Ko JJ, Xie W, Kroeger N, Lee JL, Rini BI, Knox JJ, Bjarnason GA, Srinivas S, Pal SK, Yuasa T, Smoragiewicz M, Donskov F, Kanesvaran R, et al. The International Metastatic Renal Cell Carcinoma Database Consortium model as a prognostic tool in patients with metastatic renal cell carcinoma previously treated with first-line targeted therapy: a population-based study. Lancet Oncol. 2015; 16:293-300.

62. Kroeger N, Klatte T, Birkhäuser FD, Rampersaud EN, Seligson DB, Zomorodian N, Kabbinavar FF, Belldegrun AS, Pantuck AJ. Smoking negatively impacts renal cell carcinoma overall and cancer-specific survival. Cancer. 2012; 118:1795-802.

63. Albiges L, Hakimi AA, Xie W, McKay RR, Simantov R, Lin X, Lee JL, Rini BI, Srinivas S, Bjarnason GA, Ernst $\mathrm{S}$, Wood LA, Vaishamayan UN, et al. Body mass index and metastatic renal cell carcinoma: clinical and biological correlations. J Clin Oncol. 2016; 34:3655-63.

64. Sunela KL, Kataja MJ, Kellokumpu-Lehtinen PL. Influence of body mass index and smoking on the long-term survival of patients with renal cell cancer. Clin Genitourin Cancer. 2013; 11:458-64.

65. Williams RD, Elliott AY, Stein N, Fraley EE. In vitro cultivation of human renal cell cancer. II. Characterization of cell lines. In Vitro. 1978; 14:779-86.

66. Boult J, Roberts K, Brookes MJ, Hughes S, Bury JP, Cross SS, Anderson GJ, Spychal R, Iqbal T, Tselepis C. Overexpression of cellular iron import proteins is associated with malignant progression of esophageal adenocarcinoma. Clin Cancer Res. 2008; 14:379-87. https:// doi.org/10.1158/1078-0432.CCR-07-1054.

67. Sakurai K, Sohda T, Ueda S, Tanaka T, Hirano G, Yokoyama K, Morihara D, Aanan A, Takeyama Y, Irie M, Iwata K, Syakado S, Noritomiz T, et al. Immunohistochemical demonstration of transferrin receptor 1 and 2 in human hepatocellular carcinoma tissue. Hepatogastroenterology. 2014; 61:426-30.

68. Magro G, Cataldo I, Amico P, Torrisi A, Vecchio GM, Parenti R, Asioli S, Recupero D, D'Agata V, Mucignat MT, Perris R. Aberrant expression of TfR1/CD71 in thyroid carcinomas identifies a novel potential diagnostic marker and therapeutic target. Thyroid. 2011; 21:267-77.

69. Habashy HO, Powe DG, Staka CM, Rakha EA, Ball G, Green AR, Aleskandarany M, Paish EC, Douglas Macmillan R, Nicholson RI, Ellis IO, Gee JM. Transferrin receptor (CD71) is a marker of poor prognosis in breast cancer and can predict response to tamoxifen. Breast Cancer Res Treat. 2010; 119:283-93.

70. Miller LD, Coffman LG, Chou JW, Black MA, Bergh J, D’Agostino R Jr, Torti SV, Torti FM. An iron regulatory gene signature predicts outcome in breast cancer. Cancer Res. 2011; 71:6728-37.

71. Tonik SE, Shindelman JE, Sussman HH. Transferrin receptor is inversely correlated with estrogen receptor in breast cancer. Breast Cancer Res Treat. 1986; 7:71-76.

72. Lord CJ, Ashworth A. PARP inhibitors: synthetic lethality in the clinic. Science. 2017; 355:1152-58.

73. Umemura $T$, Hasegawa R, Sai-Kato $K$, Nishikawa A, Furukawa F, Toyokuni S, Uchida K, Inoue T, Kurokawa Y. Prevention by 2-mercaptoethane sulfonate and $\mathrm{N}$-acetylcysteine of renal oxidative damage in rats treated with ferric nitrilotriacetate. Jpn J Cancer Res. 1996; 87:882-86.

74. Tong WH, Sourbier C, Kovtunovych G, Jeong SY, Vira M, Ghosh M, Romero VV, Sougrat R, Vaulont S, Viollet 
B, Kim YS, Lee S, Trepel J, et al. The glycolytic shift in fumarate-hydratase-deficient kidney cancer lowers AMPK levels, increases anabolic propensities and lowers cellular iron levels. Cancer Cell. 2011; 20:315-27.

75. Martínez-Sáez O, Gajate Borau P, Alonso-Gordoa T, Molina-Cerrillo J, Grande E. Targeting HIF-2 $\alpha$ in clear cell renal cell carcinoma: A promising therapeutic strategy. Crit Rev Oncol Hematol. 2017; 111:117-23.

76. Greene C, Sharma N, Smith G, Gross K, Kauffman EC. Iron deprivation downregulates HIF- $2 \alpha$ and induces cancerspecific apoptosis in clear cell renal cell carcinoma. J Urol. 2017; 197:e790.

77. Yamasaki T, Terai S, Sakaida I. Deferoxamine for advanced hepatocellular carcinoma. N Engl J Med. 2011; 365:576-78.

78. Donfrancesco A, Deb G, Dominici C, De Sio L, Inserra A, Boglino C, Takahashi M, Uchino J, Helson L. D-CECaT as preoperative chemotherapy for unresectable neuroblastoma in children over one year of age. Anticancer Res. 1995; 15:2347-50.

79. Saeki I, Yamamoto N, Yamasaki T, Takami T, Maeda M, Fujisawa K, Iwamoto T, Matsumoto T, Hidaka I, Ishikawa T, Uchida K, Tani K, Sakaida I. Effects of an oral iron chelator, deferasirox, on advanced hepatocellular carcinoma. World J Gastroenterol. 2016; 22:8967-77.

80. Daniels TR, Delgado T, Helguera G, Penichet ML. The transferrin receptor part II: targeted delivery of therapeutic agents into cancer cells. Clin Immunol. 2006; 121:159-76.
81. Young MF, Pressman E, Foehr ML, McNanley T, Cooper E, Guillet R, Orlando M, McIntyre AW, Lafond J, O’Brien KO. Impact of maternal and neonatal iron status on placental transferrin receptor expression in pregnant adolescents. Placenta. 2010; 31:1010-14.

82. Walker RA, Day SJ. Transferrin receptor expression in non-malignant and malignant human breast tissue. J Pathol. 1986; 148:217-24.

83. Ekblom P, Thesleff I, Saxén L, Miettinen A, Timpl R. Transferrin as a fetal growth factor: acquisition of responsiveness related to embryonic induction. Proc Natl Acad Sci USA. 1983; 80:2651-55.

84. Meyron-Holtz EG, Ghosh MC, Iwai K, LaVaute T, Brazzolotto X, Berger UV, Land W, Ollivierre-Wilson H, Grinberg A, Love P, Rouault TA. Genetic ablations of iron regulatory proteins 1 and 2 reveal why iron regulatory protein 2 dominates iron homeostasis. EMBO J. 2004; 23:386-95.

85. Basile DP, Anderson MD, Sutton TA. Pathophysiology of acute kidney injury. Compr Physiol. 2012; 2:1303-53.

86. May ME, Parmley RT, Spicer SS, Ravenel DP, May EE, Buse MG. Iron nitrilotriacetate-induced experimental diabetes in rats. J Lab Clin Med. 1980; 95:525-35. 